\title{
Climate Change Projections of Temperature and Precipitation in the Eastern Black Sea Basin, Turkey by using Multivariate Adaptive Regression Splines Statistical Downscaling Method
}

Sinan NACAR ( $\nabla$ sinannacar@hotmail.com )

Tokat Gaziosmanpaşa University https://orcid.org/0000-0003-2497-5032

Murat KANKAL

Bursa Uludağ University

Umut OKKAN

Balıkesir University

\section{Research Article}

Keywords: Eastern Black Sea Basin, Climate Change, MARS, Statistical Downscaling

Posted Date: August 17th, 2021

DOI: https://doi.org/10.21203/rs.3.rs-647619/v1

License: (c) (i) This work is licensed under a Creative Commons Attribution 4.0 International License.

Read Full License 
Climate change projections of temperature and precipitation in the Eastern Black Sea

Basin, Turkey by using multivariate adaptive regression splines statistical downscaling method

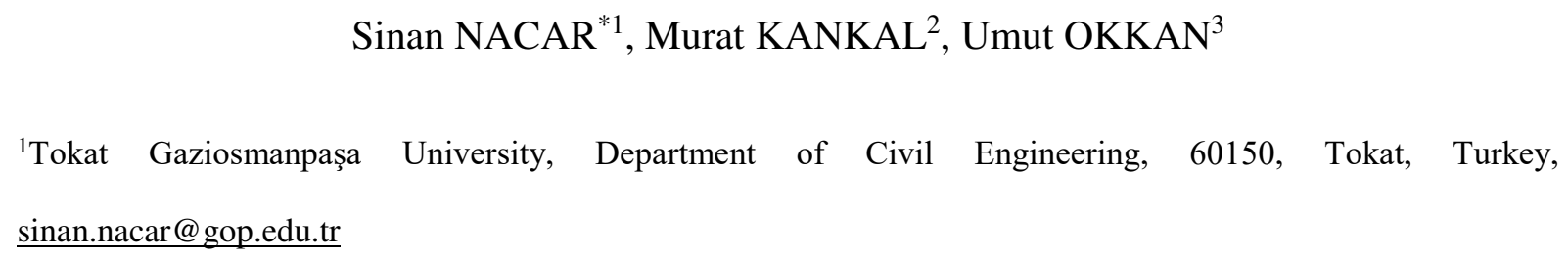

${ }^{1}$ Tokat Gaziosmanpaşa University, Department of Civil Engineering, 60150, Tokat, Turkey, sinan.nacar@gop.edu.tr

${ }^{2}$ Bursa Uludağ University, Department of Civil Engineering, 16059, Bursa, Turkey, mkankal@uludag.edu.tr

${ }^{3}$ Balıkesir University, Department of Civil Engineering, 10600, Balıkesir, Turkey, umutokkan@balikesir.edu.tr *Corresponding author: Sinan Nacar, Ph.D. (Email: sinan.nacar@gop.edu.tr)

Author

Sinan Nacar

Murat Kankal

Umut Okkan

\section{$\underline{\text { ORCID ID }}$}

0000-0003-2497-5032

0000-0003-0897-4742

0000-0003-1284-3825 


\title{
Climate change projections of temperature and precipitation in the Eastern Black Sea Basin, Turkey by using multivariate adaptive regression splines statistical downscaling method
}

\author{
Sinan $\mathrm{Nacar}^{* 1}$, Murat Kankal ${ }^{2}$, Umut Okkan ${ }^{3}$ \\ ${ }^{1}$ Tokat Gaziosmanpaşa University, Department of Civil Engineering, 60150, Tokat, Turkey, \\ sinan.nacar@gop.edu.tr \\ ${ }^{2}$ Bursa Uludağ University, Department of Civil Engineering, 16059, Bursa, Turkey, mkankal@uludag.edu.tr \\ ${ }^{3}$ Balıkesir University, Department of Civil Engineering, 10600, Balıkesir, Turkey, umutokkan@ balikesir.edu.tr \\ *Corresponding author: Sinan Nacar, Ph.D. (Email: sinan.nacar@gop.edu.tr)
}

\section{Abstract}

Climate change has recently become one of the most important issue discussed by scientists around the world. The purpose of this study is to investigate the possible effects of climate change on temperature and precipitation variables, which are among the most major climate variables in terms of their environmental and economic impact for the rainiest region of Turkey. General circulation models (GCMs) under different emission scenarios are widely used in determining possible changes in the climate system. However, the coarse resolutions of these models are unsuitable for the climate impact/adaptation studies at basin scale. In this paper, the future monthly mean temperature and precipitation for 12 station in the Eastern Black Sea Basin, Turkey were projected for three periods 2030s (2021-2050), 2060s (2051-2080), and 2090s (2081-2100) from the three GCMs, namely CNRM-CM5.1, HadGEM2-ES, and MPIESM-MR, under RCP4.5 (optimistic) and RCP8.5 (pessimistic) scenarios using the multivariate adaptive regression splines (MARS) statistical downscaling method. The statistical downscaling models were set up between the 12 potential predictor, obtained from ERAInterim reanalysis data set, and the local station data. For evaluating and the performance of the downscaling models four performance statistics namely root means square error, scatter index, mean absolute error, and the Nash Sutcliffe coefficient of efficiency, were used. Thereafter, the 
calibrated and validated models were applied to downscale future scenarios of the GCMs. The results obtained from the study proved that the downscale temperature and precipitation values correlated well with the observation values for the training (1981-2004) and test (2005-2010) periods. An average increase of 2.5 and $2.0{ }^{\circ} \mathrm{C}$ is foreseen according to the optimistic scenario and an average increase of 3.5 and $3.0{ }^{\circ} \mathrm{C}$ is foreseen according to the pessimistic scenario in the southern and northern parts of the basin, respectively. As to precipitation, a decrease is expected in the southern part of the basin but a significant increase is expected especially in spring at the stations located in the western and coastal parts of the basin.

Keywords: Eastern Black Sea Basin, Climate Change, MARS, Statistical Downscaling

\section{Introduction}

In recent years, depending on the development of technology and the increase in population, industrialization, consumption and environmental destruction have increased rapidly. Such increases have also increased the greenhouse gas emissions, which is the biggest cause of the change in the world climate (Nourani et al. 2019). The effects of changes in the climate of the regions on the hydrological cycle and therefore on water resources have a critical importance due to the fact that all life and ecosystems depend on water (Semadeni-Davies et al. 2008; Fenta Mekonnen and Disse 2018). For this reason, planners need information about the impact of climate change on hydro meteorological variables at local scale in order to determine how existing water resources will be affected under changing climatic conditions, to use resources in accordance with changing conditions, and to prepare new water resources strategies for future periods (Al-Mukhtar and Qasim 2019). Investigating how precipitation and temperature values, which are the most influential variables of the hydrological cycle and climate, will change under the effects of climate change in the future can help decision makers make effective decisions to overcome problems such as drought and flood (Nourani et al. 2019). 
General circulation models (GCMs) are the most reliable tools to predict future climate based on socio-economic and demographic factors corresponding to different emission scenarios (Ouhamdouch and Bahir 2017; Araya-Osses et al. 2020). However, one of the main problems encountered in evaluating the effects of climate change with the outputs of GCMs is that the resolutions of these models are coarse $(250$ to $600 \mathrm{~km})$. Additionally, these models do not capture well the sub grid processes, which can be very complex in mountain regions, and fail to account properly for the orographic features of those regions (Campozano et al. 2016). For these reasons, these data cannot be used directly in the analysis of the effects of hydrological and environmental factors of climate change on a regional scale (Wilby et al. 2002; Okkan and Inan 2015a; Ouhamdouch and Bahir 2017). Thus, there is a need for spatial and temporal downscaling from the GCMs into a finer scale (Al-Mukhtar and Qasim 2019). Downscaling methods have emerged as means of connecting regional-scale atmospheric predictor variables to local-scale surface weather (Huang et al. 2011). It is seen that downscaling methods are divided into two groups in the literature. These are groups of dynamic downscaling methods and statistical downscaling methods (Wilby et al. 1998; Okkan and Kirdemir 2016). The dynamic downscaling method is associated with the physically based regional climate models that are numerical models in which GCM results constitute the boundary conditions for the local climate domain (Crane and Hewitson 1998; Okkan and Inan 2015b). However, the dynamic downscaling methods are computationally expensive and include certain parameterizations to represent the processes occurring at a higher resolution than the grid space (Huang et al. 2011; Araya-Osses et al. 2020). Statistical downscaling methods establish statistical or empirical relationships between atmospheric variables in general circulation models and meteorological variables measured at station scale. These methods are inexpensive, easily applicable to different regions, have low computational cost, and are frequently used in climate change impact, risk and uncertainty studies. The disadvantage of statistical downscaling 
methods that building the appropriate statistical relationship between the large scale predictors and station-scale meteorological variables needs historical observed data having sufficient length (Huang et al. 2011; Wilby et al. 2002). Extensive details on the advantage and disadvantage of two downscaling methods can be found in Wilby and Wigley (1997) and Chen et al. (2011).

Statistical downscaling method could be classified in to regression method, weather type approaches, and stochastic weather generators (Wilby and Wigley 1997). In recent years, various statistical downscaling methods have been used for different part of the world to downscale the coarse resolution of GCMs outputs due to their ease of use. Souvignet et al. (2010) used multiple linear regression for the HadCM3 model under different emissions scenarios, considering different predictors for each meteorological station in the Upper-Elqui watershed in Coquimbo. Huang et al. (2011) used the statistical downscaling model (SDSM) method to predict future precipitation values in the Yangtze River. Fiebig-Wittmaack et al. (2012) employed a stochastic weather generator in the Elqui river basin based on the CGCM3 model under the special report on emission scenarios (SRES) scenarios Okkan and Kirdemir (2016) utilized artificial neural network (ANN) and least-squares support vector machines (LSSVM) methods in the Gediz Basin and obtained precipitation projections for the 2015-2050 period. Ouhamdouch and Bahir (2017) was also used SDSM method to reduce the maximum and minimum temperatures and precipitations in the Essaouira basin. ANN was also used by Nourani et al. (2019) for statistically downscale the outputs of GCMs to assess future changes of precipitation and mean temperature in Tabriz synoptic station at north-west of Iran.

Turkey is geographically located in a location where the climatic conditions are mild. However, due to the fact that it is surrounded by seas on three sides, the landforms and especially the mountains extending parallel to the coasts, it experiences very different climatic conditions. The Black Sea coast of the basin receives the greatest amount of rainfall and is the only region 
of Turkey that receives rainfall throughout the year. The Eastern Black Sea Basin (EBSB) averages 1,019 mm annually; this figure can reach 2,300 $\mathrm{mm}$ near Rize Province. Floods are due to heavy rainfall or to a sudden increase in air temperature, resulting in snow melt in the mountainous parts. During the period of (1955-2005), totally 51 big floods occurred in the EBSB, causing 258 deaths. In addition, it is determined that $40 \%$ of casualties caused by floods and landslides in Turkey occurred in the EBSB (Yüksek et al. 2013). All these data reveal the importance of the basin for the assessment of climate change impacts.

This study aims to determine the effects of climate change on regional temperature and precipitation variables by using statistical downscaling method. Within the scope of this study, monthly mean temperature and monthly total precipitation data for the $2021-2100$ period were produced and evaluated for 12 meteorology stations in the EBS basin, which is the basin that receives the highest rainfall in Turkey. To this end, multivariate adaptive regression splines (MARS) statistical downscaling method was used with daily observations data from the meteorological stations using large scale ERA-Interim predictors. Then, the calibrated downscaling model was applied to project the temperature and precipitation for three future time period using three GCMs (CNRM-CM5.1, HadGEM2-ES, and MPI-ESM-MR) outputs under RCP4.5 and RCP8.5 emission scenarios. As far as we know, this study will be the first study using RCP scenario data and statistical downscaling method for climate projections in the EBSB. The methodology presented in the study is thought to be useful in terms of evaluating the effects of climate change on temperature and precipitation parameters in the future periods at the basin scale. The outputs obtained from this study can be used in watershed modeling studies, water resources planning and management, reservoir operation and water budget planning of the basin.

The paper is structured in five section. Other parts of the study are as follows. The information about the study area and atmospheric variables used in statistical downscaling models are given 
in Section 2. Then the downscaling procedure and the results obtained in the study are presented in Sections 3 and 4 respectively. Finally, some conclusions of the study are given in the last section.

\section{Study area and data sets}

\subsection{Study area}

Located in the Mediterranean climate, Turkey is divided into 25 major hydrological basins (Figure 1). The EBSB is located on the northeast coast of Turkey and receives a lot of rainfall due to its geographical features and location. Therefore, it is one of Turkey's most important hydrological basins. It also forms an important part of the Caucasus Ecoregion together with the Çoruh and Aras basins (Yüksek et al. 2013).

\section{Figure 1. Approximately here}

Total basin area is $24,077 \mathrm{~km}^{2}$ and geographically located between $40^{\circ} 15^{\prime}-41^{\circ} 34^{\prime}$ north latitudes and $36^{\circ} 43^{\prime}-41^{\circ} 35^{\prime}$ east longitudes (Figure 2). The basin is surrounded by the Black Sea in the north, Kaçkar Mountains in the east, Yamanlı, Soğanlı, Kemer and Iğdır Mountains in the south and extend to the east of Çarşamba Plain in the west. With a mean annual surface water potential of $16.46 \times 10^{9} \mathrm{~m}^{3}$ in 2016 , the EBSB is of prime importance, in comparison with a mean annual groundwater potential of $0.49 \times 10^{9} \mathrm{~m}^{3}$ in 2016 (Bayazit and Avci 1997; Yüksek et al. 2013; Anilan et al. 2016; Nacar et al. 2020).

The EBSB receives significant rainfall throughout the year. The highest amount of precipitation falls around Rize, Pazar and Hopa, which are located on the north east coastline of the basin. The mean annual total precipitation at the stations in this region is around $2300 \mathrm{~mm}$. The mean annual total rainfall of the basin is around $1100 \mathrm{~mm}$. There are many streams of various sizes within the borders of the EBSB. These streams flow into the Black Sea by flowing through steep slopes and through deep valleys. As a result of the melting of the snow in the mountainous 
regions due to the increase in temperature and heavy rainfall falling on the slopes of the mountains, very big and destructive floods have occurred in the basin, which comprises of 6 provinces; Giresun, Trabzon, Rize, Artvin, Gümüşhane, and Bayburt (Ege et al. 2007; Ghiaei et al. 2018). According to the records 180 people have lost their lives in different floods and landslides that have occurred in the basin in the last 30 years.

\subsection{Meteorological data set}

The historical temperature and precipitation data for the EBSB were obtained from the Turkish State Meteorological Service. A considerable length of time series data was missed in almost all available stations and hence 12 stations which have monthly mean temperature and precipitation data covering 1981-2010 were used in this study. The location of these meteorological stations in the basin are given in Figure 2.

\section{Figure 2. Approximately here}

Stations within the basin are generally located on the coastline. Four station Bayburt (S02), Suşehri (S09), and Şebinkarahisar) (S10) outside but close to the basin were included to represent the mountainous region located in the south of the basin. Basic statistics of observed data for precipitation and temperature variables are given in Table 1 and Table 2, respectively.

\section{Table 1. Approximately here}

\section{Table 2. Approximately here}

\subsection{Reanalysis data set}

The ECMWF ERA-Interim reanalysis data set is produced with a sequential data assimilation scheme, advancing in time using a 12-hourly analysis cycles. In each cycle, available 
observations are combined with prior information from a forecast model to estimate the evolving state of the global atmosphere and its underlying surface. The analysis is then used to initialize a short-range model forecast, which provides the prior state estimates needed for the next analysis cycle. Each grid of reanalysis data set has a spatial resolution of $\left(0.75^{\circ} \times 0.75^{\circ}\right)$ (Amjad et al. 2020). The large scale predictors of ERA-Interim reanalysis dataset were compiled from the ECMWF website http://apps.ecmwf.int/datasets/. The ECMWF web application server offers a default spatial resolution grid of $0.75^{\circ}$ and also offers other spatialresolutions grids ranging from $0.125^{\circ}$ to $3^{\circ}$ based on a bilinear interpolation technique for continuous parameters (Liu et al. 2018; Amjad et al. 2020). When the studies using statistical downscaling were examined, it was seen that the atmospheric variables used differ from region to region and that any type of atmospheric variables can be used in the establishment of statistical downscaling models (Okkan and Fistikoglu 2014). In this study, atmospheric variables used in downscaling studies in recent years were used as independent variables. (Okkan and Fistikoglu 2014; Okkan and Kirdemir 2016, 2018; Serbes et al. 2019; Araya-Osses et al. 2020). The predictors extracted from the ERA-Interim reanalysis data set include air temperature, relative humidity, and geopotential height at various atmospheric levels $(200 \mathrm{hPa}$, $500 \mathrm{hPa}$ and $850 \mathrm{hPa}$ ), pressure, sea level pressure, air temperature and large-scale precipitation. The large scale predictors used in the study are given in Table 3. In Table 1 the air, press, slp, prate, hgt, and rhum represents the mean air temperature (in degree Celsius), pressure (in hectopascal), sea level pressure (in hectopascal), precipitation (in kilogram per square meter), geopotential height (in meter), and relative humidity (in percent), respectively (Okkan and Fistikoglu 2014).

Table 3. Approximately here 


\subsection{GCMs Data Set}

GCMs output data are frequently used in climate change impact studies. Although data from a single GCM can adequately model the current climate, it may not provide sufficiently accurate results in determining the effects of climate change in future time periods. For this reason, it is recommended to use more than one GCM output data set in the literature to accurately determine the effects of climate change on different variables in the future and to clearly reveal the sources of uncertainty (Knutti et al. 2010; Araya-Osses et al. 2020). Considering this recommendation, data belonging to three different GCMs, namely CNRM-CM5.1, HadGEM2ES, and MPI-ESM-MR, from CMIP5 (5. Climate Model Intercomparison Project) were used in this study. While selecting these GCMs, attention has been paid to the fact that the atmospheric variables in the ERA-Interim re analysis data set used in the establishment of downscaling models are also included in the historical, RCP4.5 and RCP8.5 scenario data sets of these GCMs (Taylor et al. 2012; Araya-Osses et al. 2020). The RCP4.5 is the stabilization scenario in which radiative forcing stabilizes at $4.5 \mathrm{~W} / \mathrm{m}^{2}$ in 2100 without ever exceeding that value (Thomson et al. 2011; Wayne 2013; Ouhamdouch and Bahir 2017). The RCP8.5 is representative of high emission scenarios and is characterized by increasing the emission over time (Riahi et al. 2011; Ouhamdouch and Bahir 2017). The large-scale data sets of the historical, RCP4.5 and RCP8.5 scenario outputs of the GCMs that were decided to be used in the study were accessed from the Earth System Grid Federation website.

\section{Methods}

\subsection{Multivariate adaptive regression spline (MARS)}

One of the most fundamental problems in engineering science is to develop an equation that can predict a dependent variable using one or more independent variables. Many researches are carried out in applied mathematics, statistics, and computer science and engineering to solve 
this problem. The main purpose of these studies is to obtain a function $(f)$ that can predict a variable $(y)$ using one or more $\left(x_{1}, x_{2}, \ldots, x_{n}\right)$ predictors. MARS is a multivariate nonparametric regression method developed by Friedman (1991) for flexible regression modeling of high dimensional data. The difference of this method from other methods is that it overcomes the limitations in the methodologies stated by Friedman (1991). One of the strongest features of this method is that it provides an extremely general regression equation while avoiding overfitting. The MARS method is capable of processing a wide range of nested predictors types and naturally combining them without removing the missing data from the data set (Friedman and Roosen 1995). In the MARS method, instead of making an assumption about the relationship between dependent and independent variables, there is an approach to reveal this relationship using the divide and conquer strategy (Zhang and Goh 2016). In this strategy, the training data set used to establish the downscaling model is divided into multi-part linear sections called splines. End points of linear segments with multiple parts are defined as knots, and linear segments between these nodes are defined as basis functions (Suman et al. 2016). Setting up a MARS-based downscaling model involves a two-step process, forward and backward. In the forward process, the model is created by iteratively selecting the best pairs of basic function that increase the model accuracy. However, the excess of selected basis functions at this process may create a complex and overfitted model with low predictive ability against new data. In order to increase the prediction capability of this model, the second stage, in other words, the backward process is started. In this process, the model is pruned by removing the ineffective basis functions from the model (Samui 2013; Khuntia et al. 2015; Tiryaki et al. 2019). More detailed information about the MARS statistical downscaling method and its applications can be found in (Friedman 1991).

In this study, the MARS method was used to obtain an equation to be used to estimate monthly average temperature and monthly total precipitation data measured from meteorology stations 
using coarse resolution atmospheric variables. The above mentioned analyzes were carried out by using the Salford Predictive Modeler 8.0 software.

\subsection{Quantile delta mapping bias correction}

It is stated in the literature that it is quite possible for the downscaling model outputs to contain some bias. This bias may be caused by different reasons such as the resolution of the GCMs used in downscaling, the selection of the estimators in the re-analysis data set, the downscaling method and the period to be projected (Okkan and Inan 2015a). Due to the different sources of these biases, it is not easy to resolve within climate models. Therefore, these biases need to be corrected after downscaling model outputs are obtained (Kim et al. 2020). Many studies have been carried out in which different bias correction methods are applied in order to correct the aforementioned bias and to make future climate data more realistic (Okkan and Inan 2015a; Zhao et al. 2017; Reiter et al. 2018; Guo et al. 2019; Kim et al. 2020; Salmani-Dehaghi and Samani 2021). In this study, the quantile delta mapping (QDM) method was used for bias correction. QDM bias correction method was developed to preserve the relative change ratio in the modeled quantiles of variables (Cannon et al. 2015; Kim et al. 2020). The basic equation of the QDM method comprises the bias-corrected value term obtained from the observational data and the relative change term $(\Delta)$ obtained from the model data, as defined in Equations 1.

$$
\begin{aligned}
& \widehat{X}_{m, p}(t)=\widehat{X}_{o: m, h: p}(t) \cdot \Delta_{m}(t) \\
& \widehat{X}_{o: m, h: p}(t)=F_{o, h}^{-1}\left[F_{m, p}^{-1}\left\{X_{m, p}(t)\right\}\right] \\
& \Delta_{m}(t)=\frac{X_{m, p}(t)}{F_{m, h}^{-1}\left[F_{m, p}^{(t)}\left\{X_{m, p}(t)\right\}\right]}
\end{aligned}
$$

where $\hat{X}_{m, p}(t)$ is the model (simulated) data at time $t$ of the projected period, $\Delta_{m}(t)$ is the relative change in the model data between the historical and future periods, $F_{m, p}^{-1}$ and $F_{o, h}^{-1}$ are the cumulative probability function (CDF) of the raw data of the statistical downscale model 
and the inverse CDF of the observed data, and $\hat{X}_{o: m, h: p}(t)$ is the bias corrected data for the historical period. Thus, the bias-corrected future projection at time $\mathrm{t}$ is given by multiplying the relative change $\Delta_{m}(t)$ by the historical bias-corrected value (Kim et al. 2020). More details about the QDM and its implementation can be found in Cannon et al. (2015) and Kim et al. (2020).

\subsection{Model evaluation statistics}

In order to evaluate the MARS based downscaling models performance with respect to the observed precipitation and temperature data four statistical performance indices, namely the rood mean square error (RMSE), scatter index (SI), mean absolute error (MAE), and NashSutcliffe (NS) were used. These performance indices are mostly used to assess the downscaling performance of statistical downscaling models (Okkan and Inan 2015a, b; Al-Mukhtar and Qasim 2019). (Moriasi et al. 2007) also emphasized the importance of the usage of RMSE and NS statistical performance indices for evaluating model performances in hydrological studies. The above mentioned model performance indices are computed as shown from the Equation 4 to 7 .

$$
\begin{aligned}
& \text { RMSE }=\sqrt{\frac{1}{n} \sum_{i=1}^{n}\left(X_{0, t}-X_{m, t}\right)^{2}} \\
& \text { SI }=\frac{\text { RMSE }}{\overline{X_{0, t}}} \\
& \text { MAE }=\frac{1}{n} \sum_{t=1}^{n}\left|X_{o, t}-X_{m, t}\right| \\
& N S=1-\left[\frac{\sum_{t=1}^{n}\left(x_{0, t}-x_{m, t}\right)^{2}}{\sum_{t=1}^{n}\left(x_{0, t}-\overline{X_{0, t}}\right)^{2}}\right]
\end{aligned}
$$

where $X_{o}$ is observed value, $X_{m}$ is the downscaled value, and $\overline{X_{o}}$ is mean value. The RMSE, SI and MAE are error index types of model evaluation statistics. The closer value to zero, the 
better model performance (Singh et al. 2005). The NS coefficient is a dimensionless model evaluation statistic where the relative magnitude of the residual variance is determined in comparison to the observed variance (Moriasi et al. 2007; Al-Mukhtar and Qasim 2019). A value of NS close to 1 indicates that the model is efficient (Okkan and Inan 2015a). General performance ratings of the NS were presented in (Moriasi et al. 2007) (Table 4).

\section{Table 4. Approximately here}

\section{Results and discussion}

\subsection{Training and testing of statistical downscaling model}

In order to determine the statistical downscaling models and the performances of these models, firstly, ERA-Interim atmospheric variables and the observed data sets were divided into two groups as training and testing. The data for the 1981-2004 (80\%) period were used in the training of the statistical downscaling models, and the remaining data for the 2005-2010 (20\%) period were used in the testing of the models. The flowchart of proposed downscaling strategy summarized in Figure 3. As can be seen in the flow chart, observed precipitation/temperature data and the selected ERA-Interim large scale predictors were turned into standardized series before being presented to the MARS-based downscaling model. Standardization is a simple bias correction technique introduced by Pan and Van Den Dool (1998). Wilby et al. (2004) have been emphasized that standardization procedure is used prior to downscaling to reduce biases in the mean and variances of GCM outputs relative to the observations or reanalysis variables. This standardization procedure has also been applied to scenario data of the GCMs data. For the standardization procedure, the approach suggested by Wilby et al. (2004) was used.

\section{Figure 3. Approximately here}

In the training period of the MARS based statistical downscaling method using reanalysis data, estimation of optimal values for the related parameters were important. Optimal parameters for 
the MARS model used in this study were determined through trial-and-error method. After the training period of the MARS-based statistical downscaling models for the temperature and precipitation variables, the performances of models for training and testing phase were assessed by means of RMSE, SI, MAE, and NS. Performance statistics calculated for the training and test data set for temperature and precipitation variables are given in Table 5 and Table 6 , respectively.

When Table 5 is examined, it is seen that NS performance statistics vary between $0.983-0.996$ and $0.979-0.995$ for training and test data sets, respectively. When these results are evaluated according to Table 4, it is seen that the models established for all stations are in the very good class. In addition, the models of all stations give very similar results for the temperature variable. Since it will be difficult to give results for all stations in terms of presentation, only the time series plots and scatter plots of the temperature prediction of training and test data sets in Hopa and Suşehri stations are given. The EBS basin shows two different climate characteristics on the northern coasts and in the south. Therefore, the time-series plots and scatter plots of temperature predictions at Suşehri station located in the south of the basin and the Hopa station located in the north are given as representative examples (Figure 4).

\section{Table 5. Approximately here}

\section{Figure 4. Approximately here}

\section{Table 6. Approximately here}

When Table 6 is examined, it is seen that the performance values calculated for the precipitation variable are lower than the values calculated for the temperature variable. For the precipitation variables, it is seen that the values of RMSE, SI, MAE and NSE performance statistics vary between 15.641-64.879 (mm), 0.330-0.461, 12.232-48.092 (mm) and 0.513-0.698 for the training data set, respectively. For the test data set, it is seen that the values of RMSE, SI, MAE 
and NSE performance statistics range between 15.172-67.295, 0.311-0.528, 12.398-51.411 and 0.470-0.777, respectively. When the calculated NS performance statistics values were evaluated according to Table 4, it was determined that the models of Gümüşhane, Rize, and Şebinkarahisar stations were in the good class for the training data set, and the remaining nine stations were in the satisfactory class. For the test data set, it was determined that only the model belonging to Ünye station was in the unsatisfactory class, while the models belonging to Hopa, Pazar, Rize, Şebinkarahisar and Trabzon stations were in the good class, and the other stations were in the satisfactory class. When the calculated performance statistics were evaluated in general, it was seen that the statistical downscaling models established for the rainfall variable gave sufficient results for the whole basin except Ünye station. As a representative example, time-series plots and scatter plots of temperature predictions at Şebinkarahisar and Ünye stations are presented in Figure 5, both for the training and testing periods.

\section{Figure 5. Approximately here}

Although the results of the MARS based statistical downscaling model in all stations for the temperature variable are in the very good class, it is not possible to say the same for the precipitation variable. (Al-Mukhtar and Qasim 2019), (Hassan, Shamsudin, and Harun 2014), and (Yang et al. 2012) have demonstrated that the downscaling can better reproduce temperature series than precipitation. This is thought to be due to the fact that the dispersion of precipitation data is more than the temperature parameter. Although the results achieved from the MARS based statistical downscaling models showed a satisfactory/good consistency in precipitation predictions at nearly all stations, the capability for extreme value estimation of employed models was found to be restricted at some stations. In the study of (Okkan and Kirdemir 2016), it was stated that this situation is extremely possible. Also, (Tripathi et al. 2006) stated in their study that statistical models may not explain all the variance of the modeled variable. 


\subsection{Downscaling outputs of three GCMs}

In the previous section, the highest performance MARS based statistical downscaling models that estimate local scale temperature and precipitation variables using large scale atmospheric variables were determined for the all stations. After determining the statistical downscaling models for each station, the large scale atmospheric predictors in the historical, RCP4.5 and RCP8.5 scenario data sets of each GCM were arranged for the basin. After preparing the scenario data for each GCM, the standardization procedure was applied. As can be seen in Figure 3, RCP data were standardized using historical scenario data. These standardized large scale predictors datasets were used as new inputs for statistical downscaling models established using large scale atmospheric predictors in the ERA-Interim reanalysis data set. Thus, standardized time series of temperature and precipitation variables for each GCM were produced for each station for the past and the future scenarios. Standardized temperature and precipitation data obtained from the MARS based statistical downscaling models were converted into their own units by applying restandardization.

Following the obtaining the time series of temperature and precipitation, a bias correction technique was used so as to lessen possible biases in MARS based models forecasts. It is possible that the obtained MARS statistical downscaling model outputs contain different biases depending on the GCM resolutions used, atmospheric variables, downscaling technique and the period in which the data is generated (Okkan and Kirdemir 2016; Kang and Moon 2017). Chen et al. (2011) and Sachindra et al. (2014) have also emphasized that correcting biases is required before use of projections in climate impact studies. After the bias correction procedure, past and future temperature and precipitation data were evaluated separately for the periods 19802005, 2021-2050, 2051-2080 and 2081-2100, respectively.

In order to have confidence in the climate change scenarios downscaled statistically from GCMs, assurance is required that the downscaled values can represent past climatic conditions 
closely (Dibike et al. 2008; Okkan and Kirdemir 2016). Therefore, the basic statistics (mean, maximum, minimum, standard deviation, and variance) of the bias-corrected and uncorrected historical scenario outputs representing the period 1980-2005 and the basic statistics of the temperature and precipitation variables of the observation data for the same period were compared for all stations. However, in this study, only the tables belonging to Akçaabat station are given due to the page limitation (Table 7 and Table 8).

When Table 7 is examined, it is seen that all statistics for the temperature variable approach the observation values, especially the monthly average values are the same as the observation values for all three GDMs. In this case, it is thought that the outputs of the RCP4.5 and RCP8.5 scenarios, which are the future optimistic and pessimistic scenarios of GDMs, may represent the region well. In this case, it is thought that the outputs of the RCP4.5 and RCP8.5 scenarios, which are the future optimistic and pessimistic scenarios of GDMs, may more accurately represent the possible changes in the temperature values of the region.

\section{Table 7. Approximately here}

When Table 8 are examined, it is seen that the bias correction procedure, as in the temperature variable, brings the values of the model outputs closer to the observation values. After the bias correction procedure, it is clearly seen that the monthly average precipitation values as well as the maximum precipitation values, which are important for the region due to floods, are close to the observation values. These results clearly show that the bias correction procedure should be used in climate change impact studies. Otherwise, it is thought that the possible effects of climate change will not be reflected correctly and may cause wrong decisions in combating climate change.

Table 8. Approximately here 
Generally, all the GCMs output prediction of monthly mean temperature and monthly total precipitation resembled in producing the observed data for base period. Therefore, it is plausible to use the GCMs data output for future prediction for the basin (Gebre and Ludwig 2015). In the final step, mean temperature and monthly precipitation of 12 meteorology station selected in and around the EBSB were projected for the three future period (2021-2050, 2051-2080, and 2081-2100) under RCP4.5 and RCP8.5 scenarios. Foreseen changes in the future periods for temperature and precipitation variables were evaluated separately.

\subsubsection{Foreseen changes in future temperature}

In order to evaluate the foreseen temperature increases in three different periods in the future, the bias-corrected outputs of three different GCMs from RCP4.5 and RCP8.5 scenarios were compared with the bias-corrected historical scenario outputs of the same GCMs (Figure 6).

\section{Figure 6. Approximately here}

The foreseen changes in monthly mean temperature values obtained from three GCMs forced under two different scenarios are similar in most of the stations. In addition, according to the results, it is expected that there will be temperature increases in all stations in all future periods. However, it was predicted that there will be a decrease in the temperature values in the winter and spring months at the Bayburt (S02) station, which is located in the southern part of the basin and has terrestrial climate characteristics. It is foreseen that the temperature increases will reach up to $10{ }^{\circ} \mathrm{C}$, especially in the summer months. Also, the increases in the projected temperature values according to the RCP8.5 scenario outputs were higher than the RCP4.5 scenario outputs. The spatial distribution for the future changes of annual mean temperature and precipitation of the EBSB (compared to base period) under scenarios RCP4.5 and RCP8.5 were built by Inverse Distance Weighted (IDW) interpolation technology with ArcGIS 10.5 software package. Maps 
showing the spatial distribution of projected changes in annual mean temperatures are given in Figure 7.

\section{Figure 7. Approximately here}

When the maps showing the changes in the annual average temperature values were examined, it was seen that there were temperature increases in all three periods of the future. Increases were between 0.5 and $4.0^{\circ} \mathrm{C}$ in the $2021-2050$ period, and up to $6.0^{\circ} \mathrm{C}$ in the $2051-2080$ period. It was observed that the highest temperature increase occurred around $7{ }^{\circ} \mathrm{C}$ at the end of the century. While the highest temperature increase was obtained from the HadGEM model outputs, the least increase was obtained from the MPI model outputs. It was observed that the temperature increases were most concentrated in the stations located in the regions with continental climate in the south of the basin. In arid areas like southern part of the EBSB, positive changes in temperature will undoubtedly accelerate the process of desertification which in turn will ultimately effect on agricultural activities in the basin. In arid areas like southern part of the EBSB, positive changes in temperature will undoubtedly accelerate the process of desertification which in turn will ultimately effect on agricultural activities in the basin (Abbasnia et al. 2016; Al-Mukhtar and Qasim 2019). Schroeer and Kirchengast (2018) stated that a warmer atmosphere can hold more water vapor, which in turn produces more intense precipitation, including precipitation intensity increases of 6-7\% per degree of warming or even more for sub-hourly precipitation (Araya-Osses et al. 2020).

\subsubsection{Foreseen changes in future precipitation}

The relative changes (\%) of monthly mean precipitation (compared to base period 1981-2005) in the EBSB under scenarios RCP4.5 and RCP8.5 are shown in Figure 8. The results obtained for the monthly mean precipitation show more spatial variability and less robustness compared to the temperature variable. The changes of seasonal mean precipitation in the EBSB under 
scenarios RCP4.5 and RCP8.5 would present obvious differences in different seasons. In summer, decreases of $60-00 \%$ are found for the south part of the basin while in spring and winter increases $60-100 \%$ are seen in the north part of the basin. The maximum change for the precipitation variable was obtained from the HadGEM model outputs, as in the temperature variable. According to the HadGEM model results, the highest increase in precipitation occurs in Pazar, Rize and Hopa stations located on the coastline of the basin. Except for Hopa, Pazar and Rize stations, a decrease in precipitation is expected throughout the basin in summer. The stations with the highest decrease are Bayburt, Giresun, and Şebinkarahisar.

The distributions of precipitation changes are shown in Figure 9 for the considered future periods (2021-2050, 2051-2080 and 2081-2100) under two RCP scenarios. According to Figure 9 , it is seen that there are decreases in annual total precipitation values in the southern part of the basin. In addition, it is seen that the increases are generally in the coastline. The highest increase in precipitation is in the stations located in the northeast of the basin. In the sub-basins where these stations are located, many flood events occurred as a result of heavy rains. Therefore, it is thought that foreseen precipitation increases in these stations may cause serious problems in the basin in the future periods. At the same time, it is thought that decreases in precipitation may lead to drought problems for stations located in the south of the basin, which already has a dry climate. Therefore, this fact highlights the importance of swift adaptation and mitigation measures in the study areas (Al-Mukhtar and Qasim 2019).

\section{Figure 8. Approximately here}

\section{Figure 9. Approximately here}

\section{Conclusions}

In this study, possible effects of climate change in the future on temperature and precipitation variables observed from 12 station in the Eastern Black Sea Basin (EBSB), Turkey were 
investigated. Large-scale GCMs outputs, which are frequently used in determining the effects of climate change in the literature, were downscaled to local scale with the multivariate adaptive regression splines (MARS) based statistical downscaling method. During the training and testing of MARS-based statistical downscaling models, atmospheric variables included in the ERA-Interim reanalysis data set as well as observed data from the meteorological stations in and around basin were used. It is highly recommended in the literature to use more than one GCM from climate change impact studies to see sources of uncertainty in models and analyze robustness of the results. Therefore, in this study, the CNRM, HadGEM and MPI outputs for the RCP4.5 and RCP8.5 emission scenarios were used to projects the future changes.

According to the main results obtained from the study, the MARS statistical downscaling method can be applied as an alternative downscaling method in order to produce reasonable results in future studies to determine the effects of climate change. Based on the results obtained from the statistical indices used to determine the performance of the models, it was seen that the MARS-based statistical downscaling models applied for temperature and precipitation variables showed very good and satisfactory/good performance, respectively. According to the results obtained from the study, temperature increases were projected for both scenarios (RCP4.5 and RCP8.5) throughout the basin. The highest temperature increases were seen in the summer months for all stations. In Gümüşhane, Bayburt, Şebinkarahisar and Suşehri stations, which are located in the south of the basin and have terrestrial climate characteristics, increases up to $10{ }^{\circ} \mathrm{C}$ were projected for all three GDM and two scenarios. Although the results obtained from all three models were similar, the models with the highest and lowest temperature increase were HadGEM and MPI, respectively.

When the simulated precipitation values for the future period are compared with the base period, the monthly and annual total precipitation values showed different patterns of variation for three different periods throughout the basin under the RCP4.5 and RCP8.5 scenarios. It was 
observed that the precipitation of the stations located in the southern part of the basin would decrease by $100 \%$ in the summer months and there would be a $50 \%$ increase in the spring months. In the regions represented by the stations in the south, a drier future is expected due to the increasing temperature and decreasing precipitation in the summer months. In addition, it was observed that the precipitation of the Rize, Pazar and Hopa stations located in the northeastern part of the basin would increase by $100 \%$ in the spring months. It is thought that the floods that occurred in this region in the past years, especially in the spring, due to shortterm heavy rains and melting snow with increasing temperatures, may increase in the future.

This study has shown that climate change that may occur under certain scenarios may seriously affect the hydrology and water resources of the EBSB, Turkey in the future. Knowing the possible effects of climate change on temperature and precipitation, which are the most important variables of hydrology, can provide basic information for decision-makers' decisions in ecological, economic, social and health fields. The authors would like to suggest further assessment of the study area with different statistical downscaling methods using a large ensemble of CMIP5 and CMIP6 GCMs data sets forced under different emission and social scenario. In addition, daily, monthly, seasonal and annual changes and cycles of other climatic variables such as maximum temperature, minimum temperature, rainy period length, dry period length can be investigated with more relative performance statistics.

Code availability: The models or codes used to develop this study are available from the corresponding author upon reasonable request.

Availability of data and materials: Some or all data that support this study's findings are available from the corresponding author upon reasonable request.

Ethical Approval: Not applicable

Consent to Participate: Not applicable

Consent to Publish: Not applicable 


\section{Author Contributions}

Conceptualization, S.N., and M.K.; Investigation, S.N., M.K. and U.O.; Methodology, S.N., M.K., and U.O.; Supervision, M.K., and U.O.; Visualization, S.N., and M.K.; Writing original draft preparation, S.N., and M.K.; Writing review and editing, M.K., and U.O.

\section{Funding}

This research received no external funding.

\section{Conflict of Interest}

The authors declare that they have no conflict of interest.

\section{Acknowledgments}

The authors are grateful to the providers of the Salford Predictive Modeler 8 software, which was employed to perform the analysis.

\section{References}

Abbasnia M, Tavousi T, Khosravi M (2016) Assessment of future changes in the maximum temperature at selected stations in Iran based on HADCM3 and CGCM3 models. AsiaPacific J Atmos Sci 52:371-377. https://doi.org/10.1007/s13143-016-0006-z

Al-Mukhtar M, Qasim M (2019) Future predictions of precipitation and temperature in Iraq using the statistical downscaling model. Arab J Geosci 12:. https://doi.org/10.1007/s12517-018-4187-x

Amjad M, Yilmaz MT, Yucel I, Yilmaz KK (2020) Performance evaluation of satellite- and model-based precipitation products over varying climate and complex topography. $\mathbf{J}$ Hydrol 584:124707. https://doi.org/10.1016/j.jhydrol.2020.124707

Anilan T, Satilmis U, Kankal M, Yuksek O (2016) Application of Artificial Neural Networks 
and regression analysis to L-moments based regional frequency analysis in the Eastern Black Sea Basin, Turkey. KSCE J Civ Eng 20:2082-2092. https://doi.org/10.1007/s12205-015-0143-4

Araya-Osses D, Casanueva A, Román-Figueroa C, et al (2020) Climate change projections of temperature and precipitation in Chile based on statistical downscaling. Clim Dyn 54:4309-4330. https://doi.org/10.1007/s00382-020-05231-4

Bayazit M, Avci I (1997) Water resources of Turkey: Potential, planning, development and management. Int J Water Resour Dev 13:443-452. https://doi.org/10.1080/07900629749566

Campozano L, Tenelanda D, Sanchez E, et al (2016) Comparison of Statistical Downscaling Methods for Monthly Total Precipitation: Case Study for the Paute River Basin in Southern Ecuador. Adv Meteorol 2016:. https://doi.org/10.1155/2016/6526341

Cannon AJ, Sobie SR, Murdock TQ (2015) Bias correction of GCM precipitation by quantile mapping: How well do methods preserve changes in quantiles and extremes? J Clim 28:6938-6959. https://doi.org/10.1175/JCLI-D-14-00754.1

Chen J, Brissette FP, Leconte R (2011) Uncertainty of downscaling method in quantifying the impact of climate change on hydrology. J Hydrol 401:190-202. https://doi.org/10.1016/j.jhydrol.2011.02.020

Crane RG, Hewitson BC (1998) Doubled CO2 precipitation changes for the Susquehanna basin: Down-scaling from the GENESIS general circulation model. Int J Climatol 18:65-76. https://doi.org/10.1002/(SICI)1097-0088(199801)18:1<65::AID-JOC222>3.0.CO;2-9

Dibike YB, Gachon P, St-Hilaire A, et al (2008) Uncertainty analysis of statistically downscaled temperature and precipitation regimes in Northern Canada. Theor Appl Climatol 91:149_ 
170. https://doi.org/10.1007/s00704-007-0299-Z

Ege B, Uzun M, Filiz MH, et al (2007) Problems encountered and solution proposals about DSI activities in the Eastern Black Sea Region. In: International Congress on River Basin Management. pp 59-67

Fenta Mekonnen D, Disse M (2018) Analyzing the future climate change of Upper Blue Nile River basin using statistical downscaling techniques. Hydrol Earth Syst Sci 22:2391-2408. https://doi.org/10.5194/hess-22-2391-2018

Fiebig-Wittmaack M, Astudillo O, Wheaton E, et al (2012) Climatic trends and impact of climate change on agriculture in an arid Andean valley. Clim Change 111:819-833. https://doi.org/10.1007/s10584-011-0200-z

Friedman JH (1991) Multivariate adaptive regression splines. Ann Stat 19:1-67

Friedman JH, Roosen CB (1995) An introduction to multivariate adaptive regression splines. Stat Methods Med Res 4:197-217. https://doi.org/10.1177/096228029500400303

Gebre SL, Ludwig F (2015) Hydrological Response to Climate Change of the Upper Blue Nile River Basin: Based on IPCC Fifth Assessment Report (AR5). J Climatol Weather Forecast 3:1-15. https://doi.org/10.4172/2332-2594.1000121

Ghiaei F, Kankal M, Anilan T, Yuksek O (2018) Regional intensity-duration-frequency analysis in the Eastern Black Sea Basin, Turkey, by using L-moments and regression analysis. Theor Appl Climatol 131:245-257. https://doi.org/10.1007/s00704-016-1953-0

Guo Q, Chen J, Zhang X, et al (2019) A new two-stage multivariate quantile mapping method for bias correcting climate model outputs. Clim Dyn 53:3603-3623. https://doi.org/10.1007/s00382-019-04729-w

Hassan Z, Shamsudin S, Harun S (2014) Application of SDSM and LARS-WG for simulating 
and downscaling of rainfall and temperature. Theor Appl Climatol 116:243-257. https://doi.org/10.1007/s00704-013-0951-8

Huang J, Zhang J, Zhang Z, et al (2011) Estimation of future precipitation change in the Yangtze River basin by using statistical downscaling method. Stoch Environ Res Risk Assess 25:781-792. https://doi.org/10.1007/s00477-010-0441-9

Kang B, Moon S (2017) Regional hydroclimatic projection using an coupled composite downscaling model with statistical bias corrector. KSCE J Civ Eng 21:2991-3002. https://doi.org/10.1007/s12205-017-1176-7

Khuntia S, Mujtaba H, Patra C, et al (2015) Prediction of compaction parameters of coarse grained soil using multivariate adaptive regression splines (MARS). Int J Geotech Eng 9:79-88. https://doi.org/10.1179/1939787914Y.0000000061

Kim S, Joo K, Kim H, et al (2020) Regional quantile delta mapping method using regional frequency analysis for regional climate model precipitation. J Hydrol 125685. https://doi.org/10.1016/j.jhydrol.2020.125685

Knutti R, Furrer R, Tebaldi C, et al (2010) Challenges in combining projections from multiple climate models. J Clim 23:2739-2758. https://doi.org/10.1175/2009JCLI3361.1

Liu Z, Liu Y, Wang S, et al (2018) Evaluation of spatial and temporal performances of ERAinterim precipitation and temperature in Mainland China. J Clim 31:4347-4365. https://doi.org/10.1175/JCLI-D-17-0212.1

Moriasi DN, Arnold JG, Liew MW Van, et al (2007) Model evaluation guidelines for systematic quantification of accuracy in watershed simulations. Trans ASABE 50:885900

Nacar S, Bayram A, Baki OT, et al (2020) Spatial Forecasting of Dissolved Oxygen. Water 
$12: 1041$

Nourani V, Razzaghzadeh Z, Baghanam AH, Molajou A (2019) ANN-based statistical downscaling of climatic parameters using decision tree predictor screening method. Theor Appl Climatol 137:1729-1746. https://doi.org/10.1007/s00704-018-2686-z

Okkan U, Fistikoglu O (2014) Evaluating climate change effects on runoff by statistical downscaling and hydrological model GR2M. Theor Appl Climatol 117:343-361. https://doi.org/10.1007/s00704-013-1005-y

Okkan U, Inan G (2015a) Statistical downscaling of monthly reservoir inflows for Kemer watershed in Turkey: Use of machine learning methods, multiple GCMs and emission scenarios. Int J Climatol 35:3274-3295. https://doi.org/10.1002/joc.4206

Okkan U, Inan G (2015b) Bayesian Learning and Relevance Vector Machines Approach for Downscaling of Monthly Precipitation. J Hydrol Eng 20:04014051. https://doi.org/10.1061/(asce)he.1943-5584.0001024

Okkan U, Kirdemir U (2016) Downscaling of monthly precipitation using CMIP5 climate models operated under RCPs. Meteorol Appl 23:514-528. https://doi.org/10.1002/met.1575

Okkan U, Kirdemir U (2018) Investigation of the Behavior of an Agricultural-Operated Dam Reservoir Under RCP Scenarios of AR5-IPCC. Water Resour Manag 32:2847-2866. https://doi.org/10.1007/s11269-018-1962-0

Ouhamdouch S, Bahir M (2017) Climate Change Impact on Future Rainfall and Temperature in Semi-arid Areas (Essaouira Basin, Morocco). Environ Process 4:975-990. https://doi.org/10.1007/s40710-017-0265-4

Pan J, Van Den Dool H (1998) Extended-range probability forecasts based on dynamical model 
output. Weather Forecast 13:983-996. https://doi.org/10.1175/15200434(1998)013<0983:ERPFBO>2.0.CO;2

Reiter P, Gutjahr O, Schefczyk L, et al (2018) Does applying quantile mapping to subsamples improve the bias correction of daily precipitation? Int J Climatol 38:1623-1633. https://doi.org/10.1002/joc.5283

Riahi K, Rao S, Krey V, et al (2011) RCP 8.5-A scenario of comparatively high greenhouse gas emissions. Clim Change 109:33-57. https://doi.org/10.1007/s10584-011-0149-y

Sachindra DA, Huang F, Barton A, Perera BJC (2014) Statistical downscaling of general circulation model outputs to precipitation-part 2: Bias-correction and future projections. Int J Climatol 34:3282-3303. https://doi.org/10.1002/joc.3915

Salmani-Dehaghi N, Samani N (2021) Development of bias-correction PERSIANN-CDR models for the simulation and completion of precipitation time series. Atmos Environ 246:117981. https://doi.org/10.1016/j.atmosenv.2020.117981

Samui P (2013) Multivariate Adaptive Regression Spline (Mars) for Prediction of Elastic Modulus of Jointed Rock Mass. Geotech Geol Eng 31:249-253. https://doi.org/10.1007/s10706-012-9584-4

Semadeni-Davies A, Hernebring C, Svensson G, Gustafsson LG (2008) The impacts of climate change and urbanisation on drainage in Helsingborg, Sweden: Combined sewer system. $\mathrm{J}$ Hydrol 350:100-113. https://doi.org/10.1016/j.jhydrol.2007.05.028

Serbes ZA, Yildirim T, Mengu GP, et al (2019) Temperature and precipitation projections under AR4 scenarios: The case of kucuk menderes basin, Turkey. J Environ Prot Ecol 20:44-51

Singh J, Knapp HV, Arnold JG, Demissie M (2005) Hydrological modeling of the Iroquois River watershed using HSPF and SWAT. J Am Water Resour Assoc 41:343-360. 
https://doi.org/10.1111/j.1752-1688.2005.tb03740.x

Souvignet M, Gaese H, Ribbe L, et al (2010) Régionalisation statistique des températures et des précipitations dans le centre-nord du Chili: Une évaluation des impacts possibles du changement climatique dans un bassin Andin aride. Hydrol Sci J 55:41-57. https://doi.org/10.1080/02626660903526045

Suman S, Khan SZ, Das SK, Chand SK (2016) Slope stability analysis using artificial intelligence techniques. Nat Hazards 84:727-748. https://doi.org/10.1007/s11069-0162454-2

Taylor KE, Stouffer RJ, Meehl GA (2012) An overview of CMIP5 and the experiment design. Bull Am Meteorol Soc 93:485-498. https://doi.org/10.1175/BAMS-D-11-00094.1

Thomson AM, Calvin K V., Smith SJ, et al (2011) RCP4.5: A pathway for stabilization of radiative forcing by 2100. Clim Change 109:77-94. https://doi.org/10.1007/s10584-011$0151-4$

Tiryaki S, Tan H, Bardak S, et al (2019) Performance evaluation of multiple adaptive regression splines, teaching-learning based optimization and conventional regression techniques in predicting mechanical properties of impregnated wood. Eur J Wood Wood Prod 77:645659. https://doi.org/10.1007/s00107-019-01416-9

Tripathi S, Srinivas V V., Nanjundiah RS (2006) Downscaling of precipitation for climate change scenarios: A support vector machine approach. J Hydrol 330:621-640. https://doi.org/10.1016/j.jhydrol.2006.04.030

Wayne GP (2013) Representative Concentration Pathways ( RCPs ). Sceptical Sci 1:1-24

Wilby RL, Charles SP, Zorita E, et al (2004) Guidelines for Use of Climate Scenarios Developed from Statistical Downscaling Methods. Analysis 27:1-27 
Wilby RL, Dawson CW, Barrow EM (2002) SDSM - A decision support tool for the assessment of regional climate change impacts. Environ Model Softw 17:145-157. https://doi.org/10.1016/s1364-8152(01)00060-3

Wilby RL, Hassan H, Hanaki K (1998) Statistical downscaling of hydrometeorological variables using general circulation model output. J Hydrol 205:1-19. https://doi.org/10.1016/S0022-1694(97)00130-3

Wilby RL, Wigley TM (1997) Downscaling general circulation model output: a review of methods and limitations. Prog Phys Geogr 21:530-548

Yang T, Li H, Wang W, et al (2012) Statistical downscaling of extreme daily precipitation, evaporation, and temperature and construction of future scenarios. Hydrol Process 26:3510-3523. https://doi.org/10.1002/hyp.8427

Yüksek Ö, Kankal M, Üçüncü O (2013) Assessment of big floods in the Eastern Black Sea Basin of Turkey. Environ Monit Assess 185:797-814. https://doi.org/10.1007/s10661$012-2592-2$

Zhang W, Goh ATC (2016) Multivariate adaptive regression splines and neural network models for prediction of pile drivability. Geosci Front 7:45-52. https://doi.org/10.1016/j.gsf.2014.10.003

Zhao T, Bennett JC, Wang QJ, et al (2017) How suitable is quantile mapping for postprocessing GCM precipitation forecasts? J Clim 30:3185-3196. https://doi.org/10.1175/JCLI-D-160652.1 
Table 1. The basic statistics of observed temperature variable

\begin{tabular}{|c|c|c|c|c|c|c|c|c|c|c|c|c|}
\hline Station & S01 & $S 02$ & S03 & S04 & S05 & S06 & S07 & S08 & 509 & $S 10$ & S11 & $\mathrm{S} 12$ \\
\hline Mean & 3.1 & -11.7 & 3.5 & -6.2 & 2.0 & 3.0 & 2.1 & 3.1 & -7.8 & -7.2 & 3.8 & 3.2 \\
\hline Minimum & 14.4 & 6.9 & 14.5 & 9.5 & 14.4 & 14.4 & 13.4 & 14.3 & 10.0 & 9.2 & 14.7 & 14.3 \\
\hline Maximum & 26.3 & 22.5 & 27.0 & 24.2 & 28.3 & 26.7 & 24.7 & 27.0 & 24.8 & 24.6 & 27.0 & 26.9 \\
\hline Standard Dev. & 6.2 & 9.0 & 6.0 & 8.0 & 6.1 & 6.3 & 6.0 & 6.3 & 8.1 & 8.1 & 6.1 & 6.2 \\
\hline Variance & 38.5 & 81.7 & 36.5 & 63.8 & 36.6 & 39.1 & 36.2 & 40.2 & 65.9 & 65.4 & 37.4 & 38.1 \\
\hline
\end{tabular}


Table 2. The basic statistics of observed precipitation variable

\begin{tabular}{|c|c|c|c|c|c|c|c|c|c|c|c|c|}
\hline Station & S01 & SO2 & S03 & S04 & S05 & S06 & S07 & S08 & SO9 & $S 10$ & $\mathrm{~S} 11$ & $\mathrm{~S} 12$ \\
\hline$\overline{\text { Mean }}$ & 0.0 & 0.0 & 0.2 & 0.0 & 9.3 & 2.3 & 15.3 & 8.2 & 0.2 & 0.0 & 0.0 & $\overline{1.6}$ \\
\hline Minimum & 61.3 & 38.2 & 107.2 & 39.2 & 188.1 & 87.4 & 175.1 & 189.0 & 36.4 & 49.1 & 70.5 & 97.5 \\
\hline Maximum & 204.0 & 145.3 & 521.6 & 141.9 & 607.5 & 251.0 & 703.2 & 516.6 & 162.2 & 187.0 & 226.1 & 298.7 \\
\hline Standard Dev. & 42.4 & 27.2 & 65.3 & 28.1 & 110.2 & 51.4 & 107.1 & 105.8 & 27.5 & 35.7 & 44.7 & 59.1 \\
\hline Variance & 1801.8 & 741.3 & 4261.2 & 790.2 & 12137.5 & 2640.3 & 11468.9 & 11194.4 & 756.3 & 1271.3 & 1996.8 & 3490.4 \\
\hline
\end{tabular}


Table 3. The large scale predictors selected from the ERA-Interim reanalysis data set for the calibration of the MARS statistical downscaling model

\begin{tabular}{|c|c|c|c|c|c|c|c|c|c|c|c|c|}
\hline Atmospheric Levels & $200 \mathrm{hPa}$ & & $500 \mathrm{hPa}$ & & & $850 \mathrm{hPa}$ & & & Surfa & & & \\
\hline Atmospheric Predictors & air200 & hgt 200 & air500 & hgt500 & rhum500 & air850 & hgt850 & rhum 850 & air & press & $s l p$ & prate \\
\hline Units & $\left({ }^{\circ} \mathrm{C}\right)$ & $(\mathrm{m})$ & $\left({ }^{\circ} \mathrm{C}\right)$ & $(\mathrm{m})$ & $(\%)$ & $\left({ }^{\circ} \mathrm{C}\right)$ & $(\mathrm{m})$ & $(\%)$ & $\left({ }^{\circ} \mathrm{C}\right)$ & $(\mathrm{mb})$ & $(\mathrm{mb})$ & $\left(\mathrm{kg} / \mathrm{m}^{2}\right)$ \\
\hline
\end{tabular}


Table 4. Performance ratings for NS

Performance rating

NS
Good

$0.65<\mathrm{NS}<0.75$
Satisfactory

$0.50<\mathrm{NS}<0.65$
Unsatisfactory

$\mathrm{NS}<0.50$ 
Table 5. Performance statistics of statistical downscaling models established for the temperature variable

\begin{tabular}{|c|c|c|c|c|c|c|c|c|}
\hline \multirow{3}{*}{$\begin{array}{l}\text { Variable } \\
\text { Data set } \\
\text { Stations }\end{array}$} & \multicolumn{7}{|c|}{ Temperature } & \multirow[b]{3}{*}{$\mathrm{NS}$} \\
\hline & \multicolumn{4}{|c|}{ Training } & \multicolumn{3}{|c|}{ Testing } & \\
\hline & RMSE & SI & MAE & NS & RMSE & SI & MAE & \\
\hline (S01) Akçabat & 0.440 & 0.031 & 0.345 & 0.995 & 0.571 & 0.037 & 0.470 & 0.992 \\
\hline (S02) Bayburt & 0.723 & 0.108 & 0.538 & 0.994 & 0.760 & 0.099 & 0.600 & 0.993 \\
\hline (S03) Giresun & 0.474 & 0.033 & 0.367 & 0.994 & 0.877 & 0.058 & 0.628 & 0.979 \\
\hline (S04) Gümüşhane & 0.503 & 0.054 & 0.407 & 0.996 & 0.591 & 0.058 & 0.461 & 0.995 \\
\hline (S05) Hopa & 0.768 & 0.054 & 0.565 & 0.983 & 1.210 & 0.080 & 0.894 & 0.967 \\
\hline (S06) Ordu & 0.384 & 0.027 & 0.307 & 0.996 & 0.533 & 0.035 & 0.443 & 0.993 \\
\hline (S07) Pazar & 0.446 & 0.034 & 0.346 & 0.994 & 0.498 & 0.035 & 0.400 & 0.993 \\
\hline (S08) Rize & 0.389 & 0.028 & 0.308 & 0.996 & 0.452 & 0.030 & 0.371 & 0.995 \\
\hline (S09) Suşehri & 0.518 & 0.053 & 0.391 & 0.996 & 0.602 & 0.056 & 0.476 & 0.995 \\
\hline (S10) Şebinkarahisar & 0.555 & 0.062 & 0.433 & 0.995 & 0.591 & 0.058 & 0.456 & 0.995 \\
\hline (S11) Trabzon & 0.426 & 0.029 & 0.334 & 0.995 & 0.436 & 0.028 & 0.350 & 0.995 \\
\hline (S12) Ünye & 0.427 & 0.030 & 0.335 & 0.995 & 0.630 & 0.042 & 0.495 & 0.990 \\
\hline
\end{tabular}


Table 6. Performance statistics of statistical downscaling models established for the precipitation variable

\begin{tabular}{|c|c|c|c|c|c|c|c|c|}
\hline \multirow{3}{*}{$\begin{array}{l}\text { Variable } \\
\text { Data set } \\
\text { Station }\end{array}$} & \multicolumn{8}{|c|}{ Precipitation } \\
\hline & \multicolumn{4}{|c|}{ Performance statistics for training dataset } & \multicolumn{4}{|c|}{ Performance statistics for testing dataset } \\
\hline & RMSE & SI & MAE & NS & RMSE & SI & MAE & $\mathrm{NS}$ \\
\hline (S01) Akçabat & 28.186 & 0.457 & 21.845 & 0.568 & 24.966 & 0.419 & 19.952 & 0.621 \\
\hline (S02) Bayburt & 16.633 & 0.446 & 12.929 & 0.619 & 19.260 & 0.458 & 14.539 & 0.529 \\
\hline (S03) Giresun & 37.542 & 0.353 & 28.100 & 0.609 & 58.500 & 0.528 & 35.174 & 0.501 \\
\hline (S04) Gümüşhane & 15.641 & 0.411 & 12.227 & 0.671 & 18.474 & 0.423 & 14.443 & 0.642 \\
\hline (S05) Hopa & 64.816 & 0.346 & 48.092 & 0.639 & 67.295 & 0.352 & 51.411 & 0.680 \\
\hline (S06) Ordu & 31.777 & 0.367 & 24.026 & 0.609 & 32.019 & 0.355 & 25.338 & 0.641 \\
\hline (S07) Pazar & 64.879 & 0.376 & 47.180 & 0.628 & 58.227 & 0.314 & 48.100 & 0.717 \\
\hline (S08) Rize & 61.446 & 0.330 & 47.728 & 0.656 & 62.511 & 0.313 & 50.159 & 0.671 \\
\hline (S09) Suşehri & 16.706 & 0.461 & 12.232 & 0.641 & 16.198 & 0.434 & 12.998 & 0.609 \\
\hline (S10) Şebinkarahisar & 20.041 & 0.407 & 15.042 & 0.698 & 15.172 & 0.311 & 12.398 & 0.777 \\
\hline (S11) Trabzon & 30.784 & 0.434 & 22.954 & 0.513 & 26.438 & 0.382 & 20.488 & 0.682 \\
\hline (S12) Ünye & 37.314 & 0.391 & 27.224 & 0.588 & 45.177 & 0.427 & 32.419 & 0.470 \\
\hline
\end{tabular}


Table 7. Comparison of the basic statistics of the observation data of the (S01) Akçaabat station temperature variable for the period of 1980-2005 with the statistics of the bias corrected and uncorrected GCM historical scenario data

\begin{tabular}{|c|c|c|c|c|c|c|c|c|c|c|c|c|}
\hline \multicolumn{13}{|l|}{ Observed } \\
\hline Month & 1 & 2 & 3 & 4 & 5 & 6 & 7 & 8 & 9 & 10 & 11 & 12 \\
\hline$\overline{\text { Mean }}$ & 7 & 6.3 & 7.6 & 11.2 & 15.3 & 20 & 23 & 23.2 & 20 & 16.1 & 11.5 & 8.7 \\
\hline Maximum & 9.2 & 8.6 & 10.6 & 14.4 & 17.1 & 21.3 & 25.3 & 25.1 & 22 & 18.2 & 13.6 & 12.5 \\
\hline Minimum & 3.8 & 3.1 & 4.9 & 8.8 & 13.7 & 19 & 20.5 & 20.6 & 17.7 & 14 & 8.2 & 6 \\
\hline Standard Dev. & 1.7 & 1.5 & 1.4 & 1.4 & 0.9 & 0.6 & 1.1 & 1 & 1 & 1.1 & 1.3 & 1.6 \\
\hline Variance & 2.8 & 2.2 & 2.1 & 1.9 & 0.8 & 0.4 & 1.3 & 1.1 & 1.1 & 1.3 & 1.7 & 2.6 \\
\hline \multicolumn{13}{|c|}{ CNRM historical } \\
\hline Mean & 6 & 6.5 & 9 & 11.4 & 13.9 & 18.5 & 23.4 & 24.1 & 21.2 & 17.2 & 12.2 & 8.1 \\
\hline Maximum & 9 & 9.5 & 11.5 & 12.7 & 15.2 & 22.9 & 27.4 & 27.3 & 23.2 & 18.9 & 14.7 & 10.5 \\
\hline Minimum & 2.2 & 4.2 & 6.8 & 9.7 & 12.8 & 14.9 & 21.2 & 22.6 & 20 & 13 & 8.9 & 2.6 \\
\hline Standard Dev. & 1.7 & 1.5 & 1.3 & 0.7 & 0.7 & 1.8 & 1.2 & 1.3 & 1 & 1.1 & 1.8 & 1.6 \\
\hline Variance & 3 & 2.3 & 1.7 & 0.5 & 0.4 & 3.1 & 1.3 & 1.7 & 0.9 & 1.3 & 3.1 & 2.5 \\
\hline \multicolumn{13}{|c|}{ CNRM historical bias corrected } \\
\hline Mean & 7 & 6.3 & 7.6 & 11.2 & 15.3 & 20 & 23 & 23.2 & 20 & 16.1 & 11.5 & 8.7 \\
\hline Maximum & 9.9 & 9.2 & 10.3 & 13.8 & 17.1 & 21.6 & 26.9 & 25.8 & 22.1 & 17.7 & 13.4 & 11.1 \\
\hline Minimum & 3.4 & 4.1 & 5.2 & 7.8 & 13.9 & 18.8 & 20.9 & 22 & 18.8 & 11.9 & 9.2 & 3 \\
\hline Standard Dev. & 1.7 & 1.5 & 1.4 & 1.4 & 0.9 & 0.6 & 1.1 & 1 & 1 & 1.1 & 1.3 & 1.6 \\
\hline Variance & 2.8 & 2.2 & 2.1 & 1.9 & 0.8 & 0.4 & 1.3 & 1.1 & 1.1 & 1.3 & 1.7 & 2.6 \\
\hline \multicolumn{13}{|c|}{ HadGEM historical } \\
\hline$\overline{\text { Mean }}$ & 5.1 & 6.3 & 9.5 & 13.7 & 18.4 & 21 & 22.6 & 21.7 & 18.8 & 16.8 & 10.8 & 7.1 \\
\hline Maximum & 9.4 & 9 & 12.3 & 15.9 & 21.7 & 23.9 & 25.1 & 23.9 & 20.6 & 18.8 & 14 & 10.1 \\
\hline Minimum & -0 & 2.7 & 5.6 & 10.8 & 15.3 & 19.5 & 19.6 & 20.1 & 16.5 & 14 & 7.4 & 3.4 \\
\hline Standard Dev. & 2 & 1.7 & 1.6 & 1.3 & 1.3 & 1 & 1.4 & 1.1 & 1.1 & 1.2 & 1.7 & 1.7 \\
\hline Variance & 4 & 2.7 & 2.6 & 1.6 & 1.7 & 1 & 1.9 & 1.1 & 1.1 & 1.5 & 2.7 & 3 \\
\hline \multicolumn{13}{|c|}{ HadGEM historical bias corrected } \\
\hline$\overline{\text { Mean }}$ & 7 & 6.3 & 7.6 & 11.2 & 15.3 & 20 & 23 & 23.2 & 20 & 16.1 & 11.5 & 8.7 \\
\hline Maximum & 11 & 8.7 & 10.1 & 13.6 & 17.5 & 21.7 & 25.1 & 25.3 & 21.7 & 17.9 & 14 & 11.5 \\
\hline Minimum & 2.7 & 3.1 & 4.1 & 8.1 & 13.3 & 19 & 20.5 & 21.6 & 17.8 & 13.5 & 8.9 & 5.3 \\
\hline Standard Dev. & 1.7 & 1.5 & 1.4 & 1.4 & 0.9 & 0.6 & 1.1 & 1 & 1 & 1.1 & 1.3 & 1.6 \\
\hline Variance & 2.8 & 2.2 & 2.1 & 1.9 & 0.8 & 0.4 & 1.3 & 1.1 & 1.1 & 1.3 & 1.7 & 2.6 \\
\hline \multicolumn{13}{|l|}{ MPI historical } \\
\hline$\overline{\text { Mean }}$ & 4.6 & 6.8 & 9.9 & 15.2 & 16.6 & 19.5 & 21.5 & 22.8 & 20.9 & 15.8 & 11.4 & $\overline{6.6}$ \\
\hline Maximum & 6.8 & 10.8 & 14.4 & 18 & 18.6 & 21.3 & 24 & 25.1 & 24.9 & 19.1 & 14.4 & 9.2 \\
\hline Minimum & 0.9 & 0.4 & 6.2 & 10.5 & 14.8 & 17 & 18.7 & 19.4 & 16.7 & 12.5 & 7.9 & 2.6 \\
\hline Standard Dev. & 1.6 & 2.3 & 2.2 & 1.9 & 1.2 & 1.2 & 1.2 & 1.5 & 1.9 & 1.6 & 1.8 & 1.3 \\
\hline Variance & 2.5 & 5.2 & 4.7 & 3.5 & 1.4 & 1.5 & 1.5 & 2.3 & 3.6 & 2.6 & 3.3 & 1.8 \\
\hline \multicolumn{13}{|c|}{ MPI historical bias corrected } \\
\hline$\overline{\text { Mean }}$ & 7 & 6.3 & 7.6 & 11.2 & 15.3 & 20 & 23 & 23.2 & 20 & 16.1 & 11.5 & 8.7 \\
\hline Maximum & 9.3 & 9 & 10.6 & 13.2 & 16.8 & 20.9 & 25.2 & 24.9 & 22.2 & 18.4 & 13.7 & 11.8 \\
\hline Minimum & 3.1 & 2.2 & 5.2 & 7.7 & 14 & 18.7 & 20.5 & 20.9 & 17.7 & 13.8 & 9.1 & 3.8 \\
\hline Standard Dev. & 1.7 & 1.5 & 1.4 & 1.4 & 0.9 & 0.6 & 1.1 & 1 & 1 & 1.1 & 1.3 & 1.6 \\
\hline Variance & 2.8 & 2.2 & 2.1 & 1.9 & 0.8 & 0.4 & 1.3 & 1.1 & 1.1 & 1.3 & 1.7 & 2.6 \\
\hline
\end{tabular}


Table 8. Comparison of the basic statistics of the observation data of the (S01) Akçaabat station precipitation variable for the period of 1980-2005 with the statistics of the bias corrected and uncorrected GCM historical scenario data

\begin{tabular}{|c|c|c|c|c|c|c|c|c|c|c|c|c|}
\hline \multicolumn{13}{|l|}{ Observed } \\
\hline Month & 1 & 2 & 3 & 4 & 5 & 6 & 7 & 8 & 9 & 10 & 11 & 12 \\
\hline Mean & 76.6 & 64.6 & 51 & 48.8 & 42.7 & 48.1 & 25.1 & 40.6 & 55.5 & 113.3 & 97.9 & 76.3 \\
\hline Maximum & 203.5 & 192.2 & 96.1 & 89.1 & 69.1 & 90.4 & 78 & 88.8 & 154 & 204 & 189.4 & 191 \\
\hline Minimum & 9.8 & 26.4 & 9.7 & 19.1 & 9.8 & 7.9 & 2.6 & 9.6 & 3.2 & 35.5 & 4.7 & 18.2 \\
\hline Standard Dev. & 53.8 & 40.4 & 20.7 & 20.7 & 15.9 & 21.8 & 17.4 & 21.6 & 32.6 & 48.7 & 52.8 & 45.5 \\
\hline Variance & 2890 & 1634 & 429 & 430 & 254 & 476 & 303 & 465 & 1060 & 2372 & 2786 & 2070 \\
\hline \multicolumn{13}{|c|}{ CNRM historical } \\
\hline$\overline{\text { Mean }}$ & 85.3 & 65.4 & 57.7 & 51.2 & 48.4 & 40.9 & 35.1 & 37.6 & 57.2 & 85.1 & 87.6 & 92.4 \\
\hline Maximum & 150.1 & 98.9 & 89.4 & 88.9 & 62.1 & 52.7 & 46.2 & 121.6 & 106 & 195 & 128.9 & 245.6 \\
\hline Minimum & 49.2 & 39.7 & 42.1 & 36.1 & 32.6 & 29.9 & 16.8 & 24.6 & 39.2 & 48.5 & 37 & 34.4 \\
\hline Standard Dev. & 27.2 & 17.1 & 12.2 & 10.7 & 7.7 & 6.1 & 6.7 & 18.3 & 15.3 & 30.8 & 28.3 & 50.8 \\
\hline Variance & 742 & 292 & 150 & 114 & 59 & 38 & 44 & 335 & 233 & 952 & 799 & 2582 \\
\hline \multicolumn{13}{|c|}{ CNRM historical bias corrected } \\
\hline$\overline{\text { Mean }}$ & 76.2 & 64.4 & 50.9 & 48.6 & 42.7 & 48 & 25.1 & 40.4 & 55 & 113.1 & 98 & 76.2 \\
\hline Maximum & 221.8 & 151.4 & 109.9 & 133.5 & 72.8 & 93.8 & 56.9 & 142.3 & 179 & 293.8 & 176.3 & 216 \\
\hline Minimum & 16.9 & 14.7 & 26.1 & 22 & 14.7 & 15.4 & 0.4 & 25.2 & 20.6 & 56.7 & 18.5 & 25.3 \\
\hline Standard Dev. & 54.8 & 40.5 & 21.6 & 22.3 & 15.4 & 21.6 & 15 & 22.1 & 36.1 & 49.5 & 50.4 & 45.8 \\
\hline Variance & 3001 & 1640 & 468 & 499 & 236 & 467 & 226 & 489 & 1302 & 2452 & 2544 & 2100 \\
\hline \multicolumn{13}{|c|}{ HadGEM historical } \\
\hline$\overline{\text { Mean }}$ & 76.3 & 72.5 & 65.1 & 53.6 & 47 & 38.6 & 22.7 & 33.2 & 62.8 & 77 & 97.5 & 82 \\
\hline Maximum & 128.6 & 121.9 & 96.4 & 73.1 & 55.9 & 43.6 & 36.6 & 45.5 & 82.2 & 139.2 & 180.3 & 175.2 \\
\hline Minimum & 0.1 & 47.3 & 48.3 & 41.4 & 39.1 & 32.5 & 0.1 & 12.2 & 45.6 & 39.6 & 0.1 & 48.4 \\
\hline Standard Dev. & 27.5 & 18.7 & 12.1 & 7.5 & 4.5 & 2.9 & 10.3 & 6.7 & 10 & 29.3 & 41.2 & 31.6 \\
\hline Variance & 757 & 349 & 146 & 57 & 20 & 9 & 107 & 45 & 101 & 858 & 1697 & 996 \\
\hline \multicolumn{13}{|c|}{ HadGEM historical bias corrected } \\
\hline$\overline{\text { Mean }}$ & 77.2 & 64.1 & 50.9 & 48.7 & 42.7 & 48 & 25.7 & 40.7 & 55.3 & 113.2 & 98.4 & 76 \\
\hline Maximum & 185.8 & 189.9 & 110.9 & 111.2 & 77.5 & 88.9 & 48.6 & 83.4 & 127 & 218.2 & 206.9 & 223.6 \\
\hline Minimum & 0 & 18 & 24.4 & 19.7 & 18.6 & 13 & 0 & 1 & 12.1 & 52.3 & 0 & 30.3 \\
\hline Standard Dev. & 47.7 & 43.5 & 21.1 & 21.3 & 16.2 & 21.1 & 14.4 & 18.3 & 31.6 & 48.8 & 50.4 & 46.6 \\
\hline Variance & 2272 & 1890 & 445 & 453 & 261 & 445 & 208 & 336 & 1001 & 2384 & 2544 & 2173 \\
\hline \multicolumn{13}{|l|}{ MPI historical } \\
\hline$\overline{\text { Mean }}$ & 100.9 & 62.2 & 56.1 & 44.4 & 51.1 & 50.3 & 41.4 & 39.8 & 52.9 & 80.6 & 71.4 & 133.4 \\
\hline Maximum & 353.4 & 111.7 & 90.8 & 62 & 76.3 & 86.3 & 56.9 & 56.5 & 97.1 & 112.3 & 103.4 & 285.7 \\
\hline Minimum & 44.5 & 33.4 & 33.7 & 23.2 & 39.1 & 36.9 & 30.3 & 25.8 & 34.4 & 46.2 & 51.8 & 48.5 \\
\hline Standard Dev. & 62.8 & 16.9 & 13.5 & 8.6 & 9.6 & 10.8 & 7.8 & 7.2 & 16 & 17.2 & 16.2 & 72 \\
\hline Variance & 3948 & 284 & 183 & 73 & 93 & 116 & 61 & 52 & 257 & 297 & 262 & 5178 \\
\hline \multicolumn{13}{|c|}{ MPI historical bias corrected } \\
\hline$\overline{\text { Mean }}$ & 76.1 & 64.1 & 50.9 & 48.9 & 42.6 & 47.9 & 25 & 40.5 & 55.1 & 113.3 & 97.5 & 76.2 \\
\hline Maximum & 300.9 & 205.7 & 108.1 & 94.9 & 88.6 & 133.4 & 65.1 & 98 & 157 & 208.3 & 211.9 & 173.8 \\
\hline Minimum & 29.1 & 10.7 & 19.9 & 9 & 23.8 & 22.7 & 5.5 & 8.3 & 20.9 & 31.4 & 39.5 & 24 \\
\hline Standard Dev. & 55.2 & 43.2 & 21.3 & 19.3 & 16.7 & 23.4 & 17.4 & 21.6 & 34.8 & 47 & 53.7 & 45.7 \\
\hline Variance & 3052 & 1864 & 454 & 373 & 279 & 546 & 304 & 464 & 1209 & 2210 & 2884 & 2087 \\
\hline
\end{tabular}




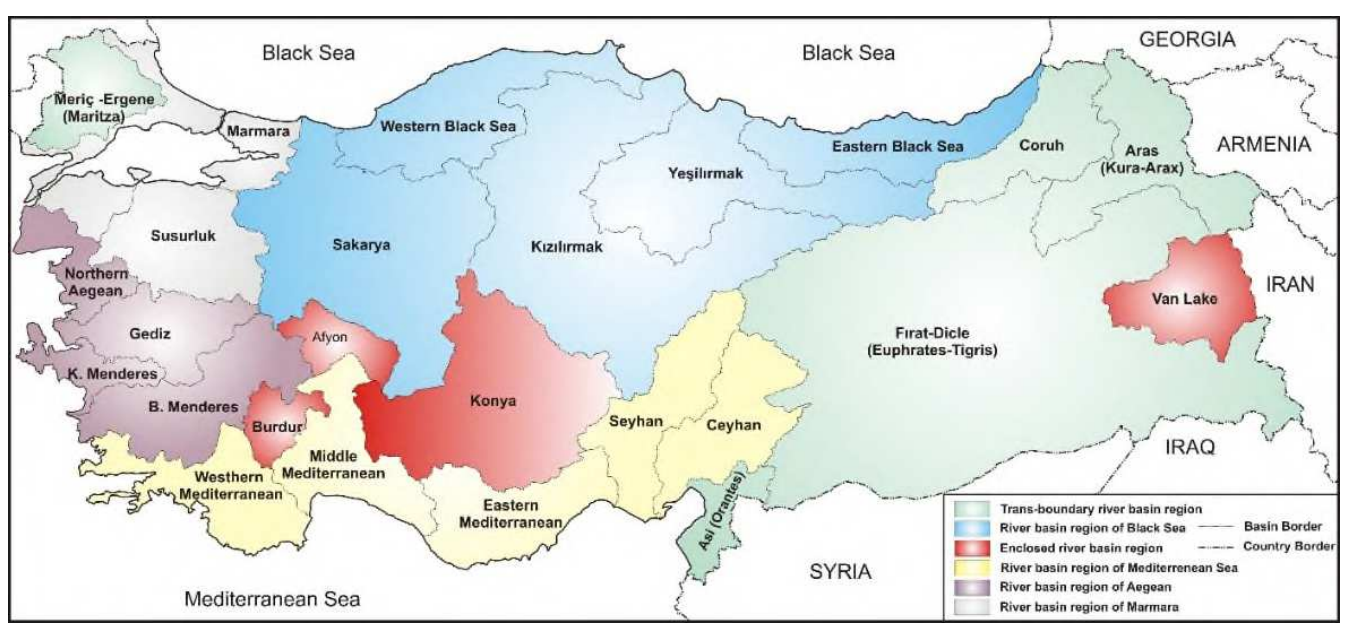

Figure 1. Hydrological basins in Turkey 


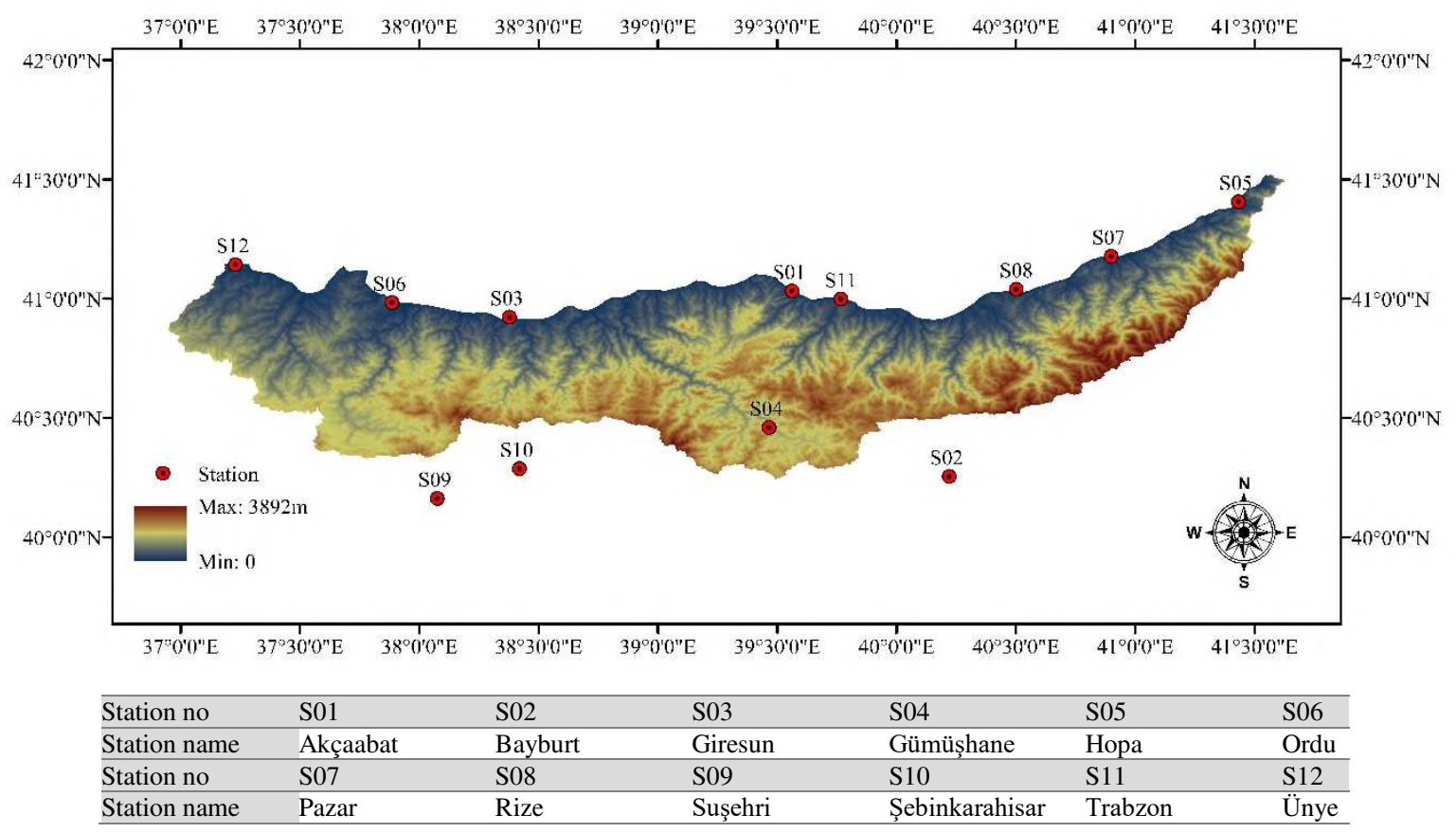

Figure 2. The locations and names of the meteorological stations used in the study and digital elevation model of the EBS basin. 


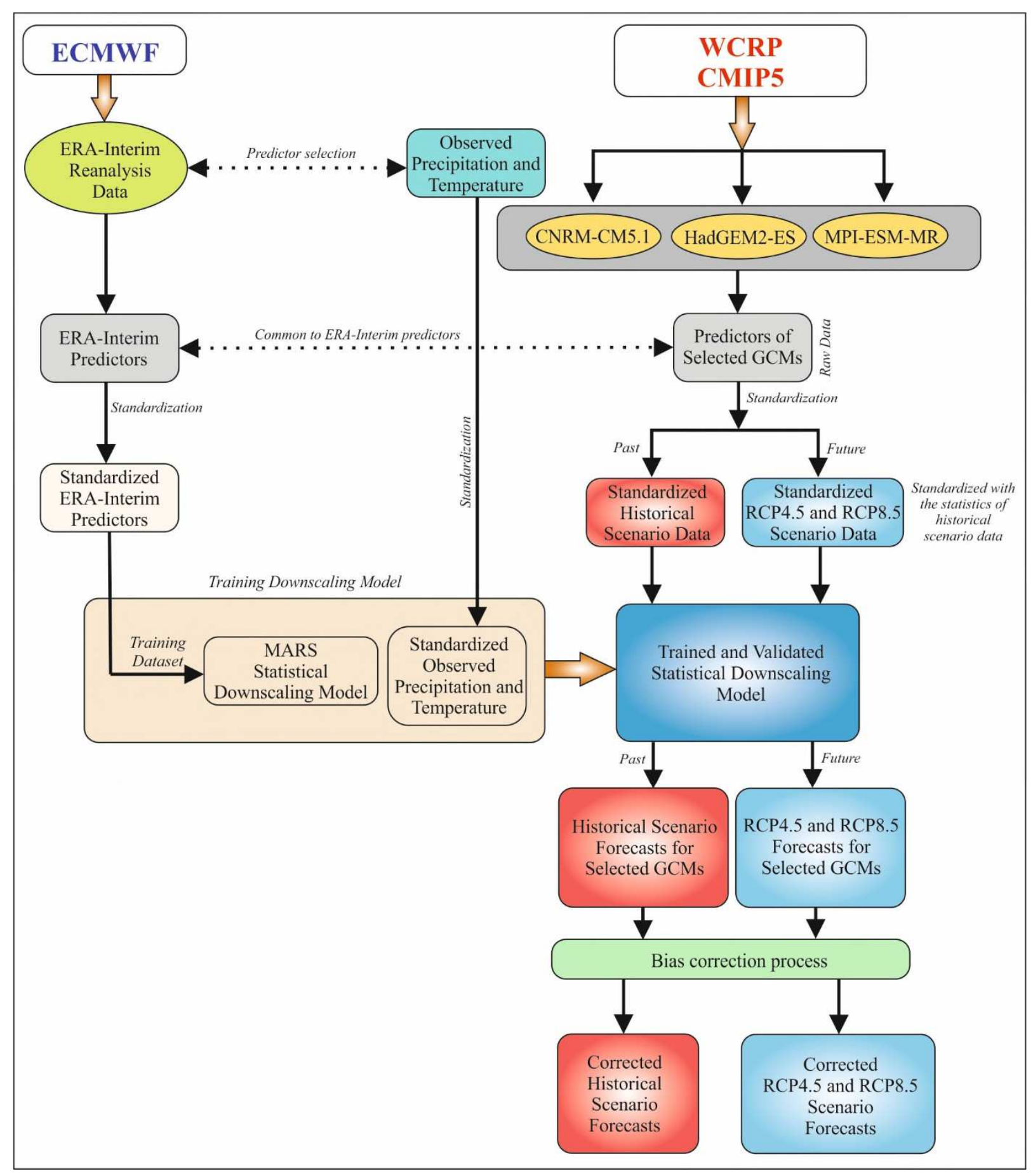

Figure 3. Flow chart of the statistical downscaling strategy applied in the study 

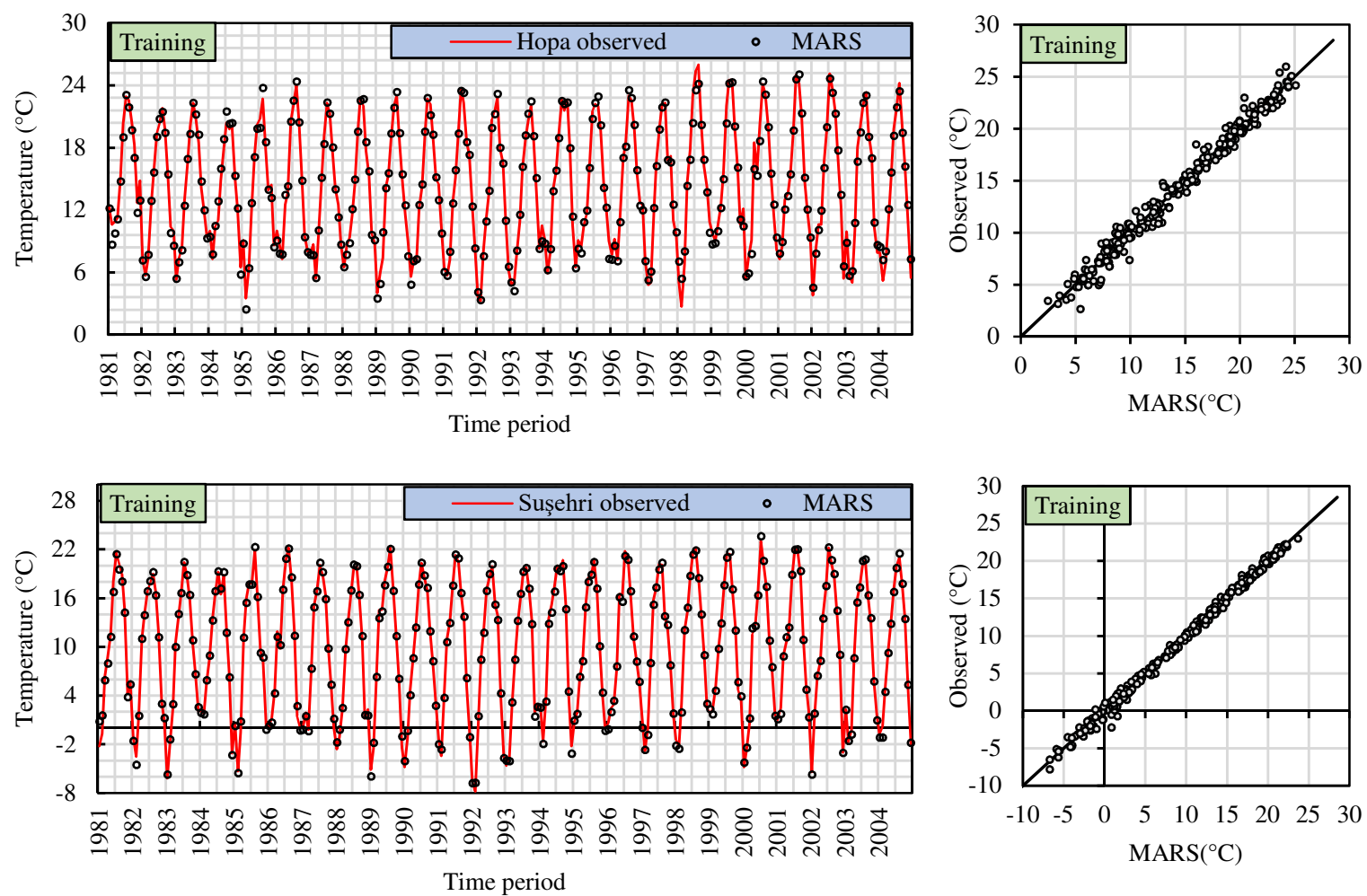

(a)
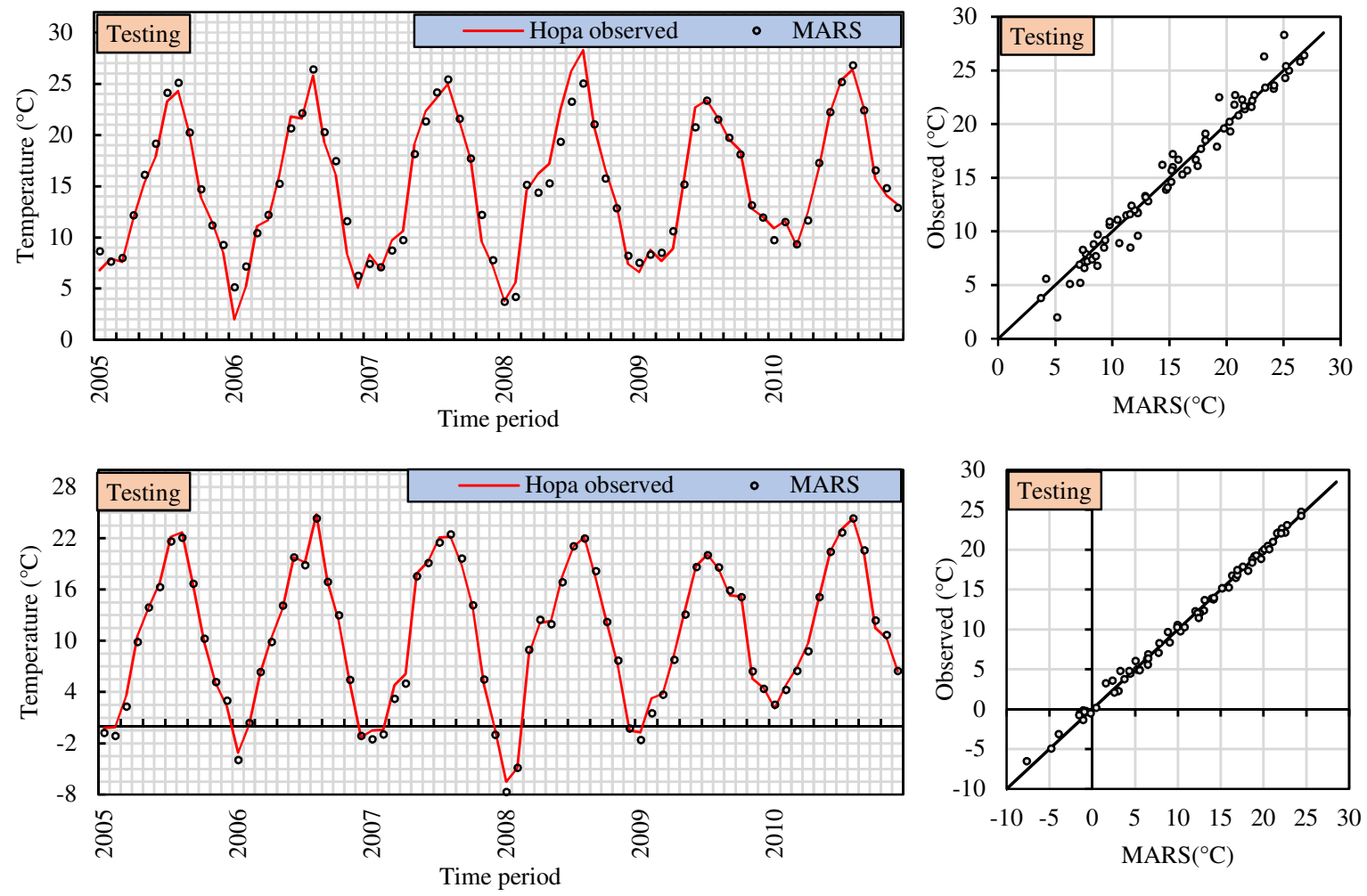

(b)

Figure 4. Temperature predictions of Hopa and Suşehri stations derived from the MARS statistical downscaling model for the (a) training and (b) testing data sets 

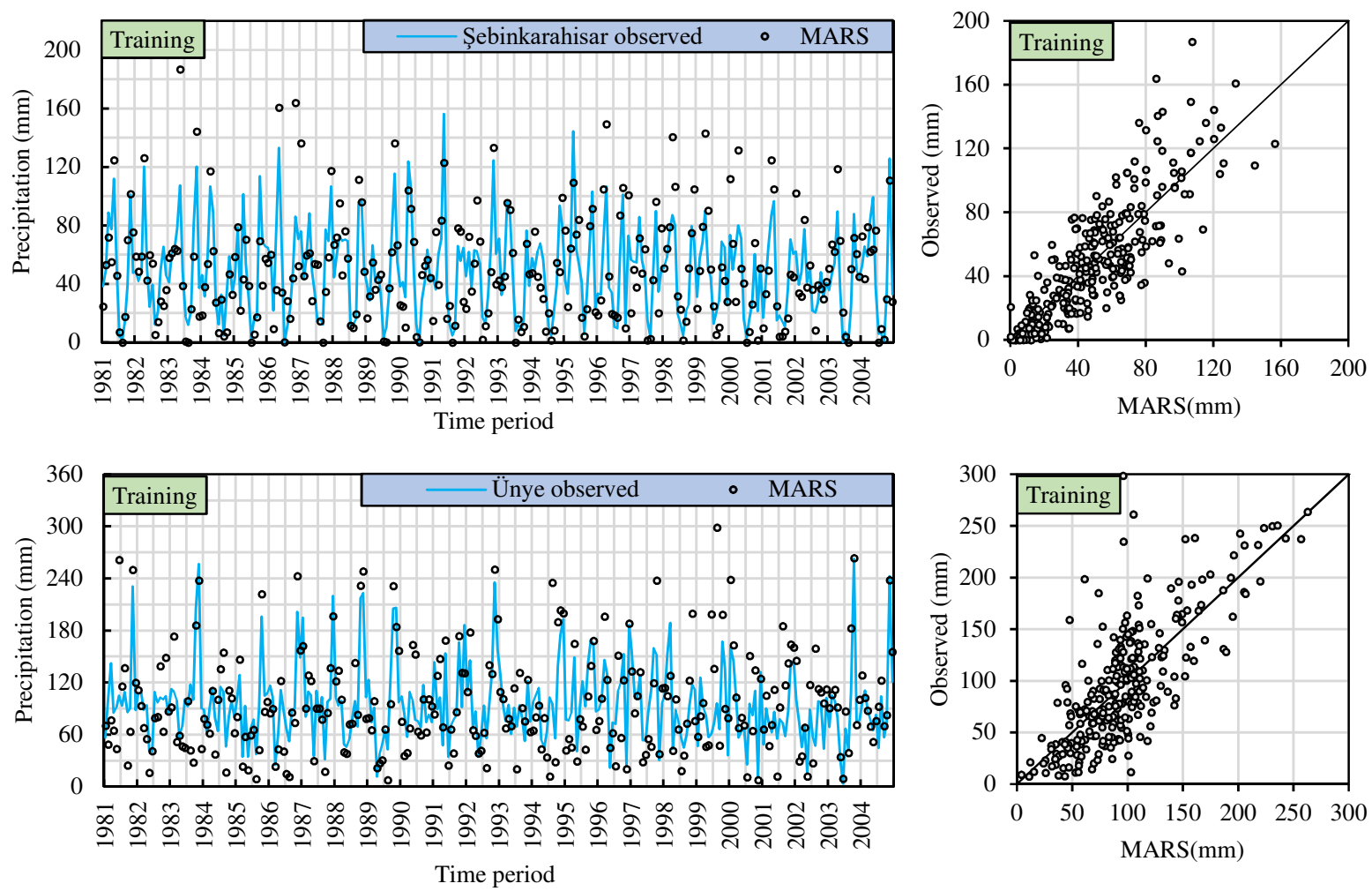

(a)
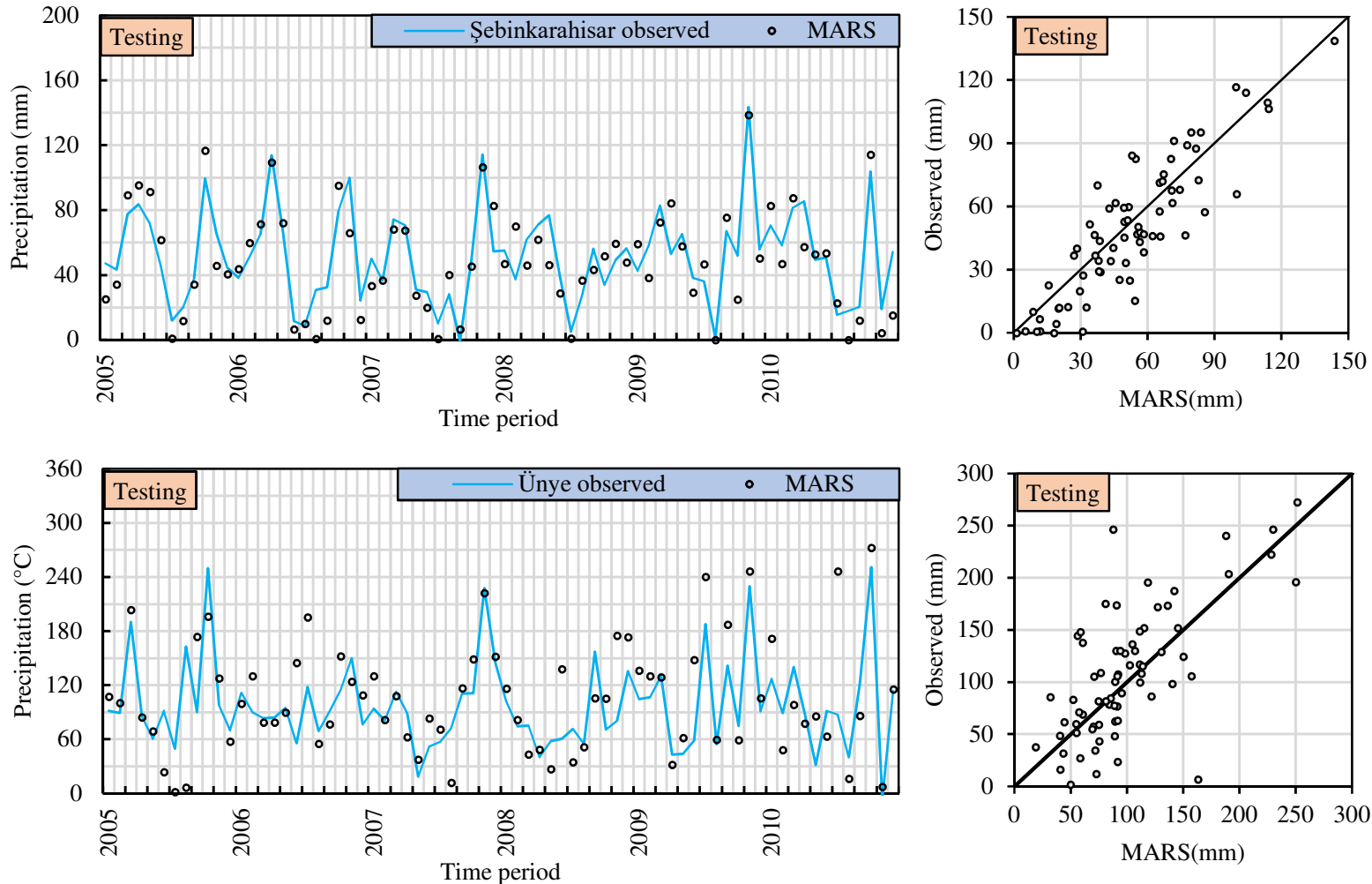

(b)

Figure 5. Precipitation predictions of Şebinkarahisar and Ünye stations derived from the MARS statistical downscaling model for the (a) training and (b) testing data sets 


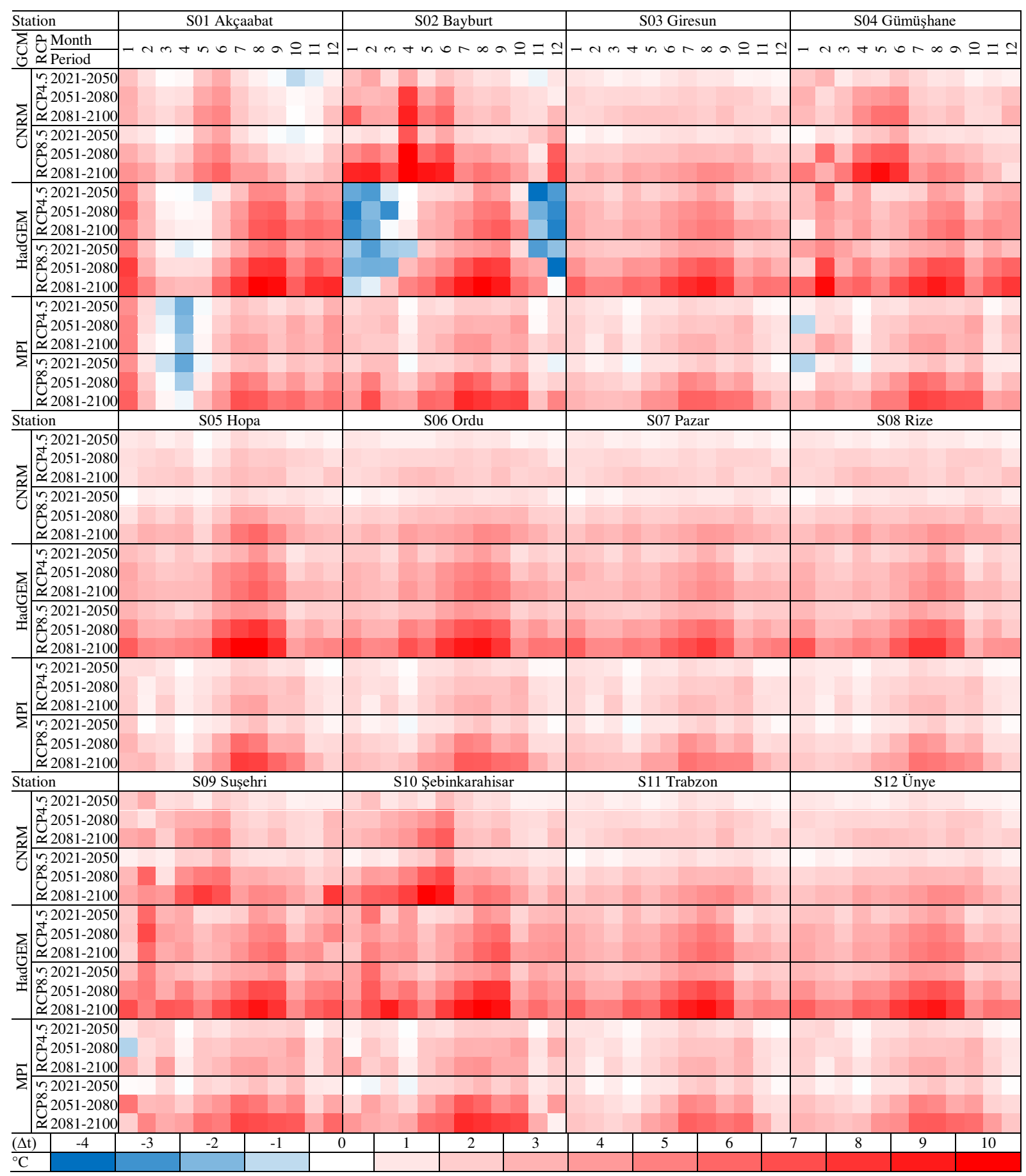

Figure 6. Temperature changes (in ${ }^{\circ} \mathrm{C}$ ) in relation to the $1980-2005$ historical scenario period for RCP4.5 and RCP8.5 scenarios. 


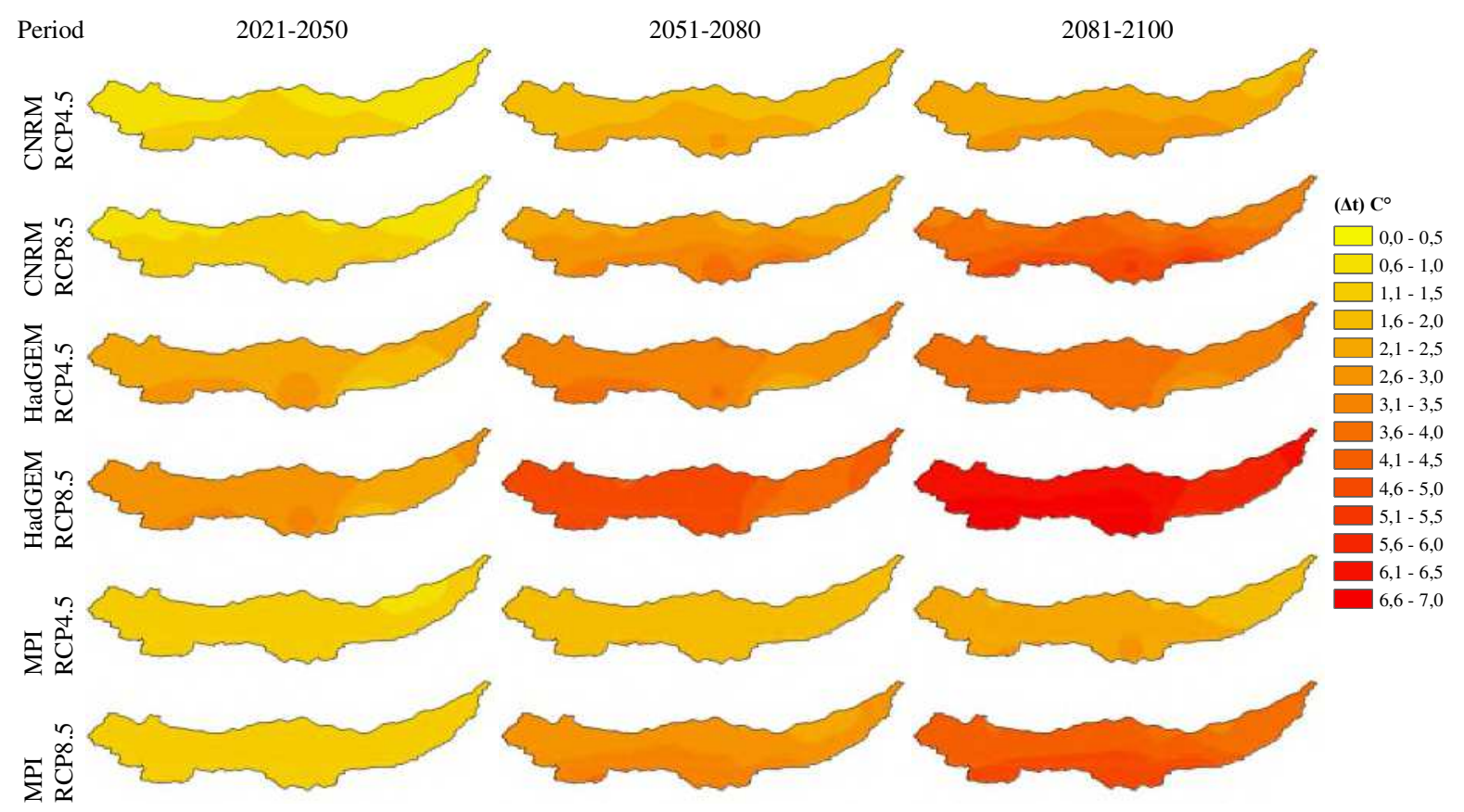

Figure 7. Spatial distribution for the change of monthly mean temperature (compared to base period) in future periods under scenarios RCP4.5 and RCP8.5 


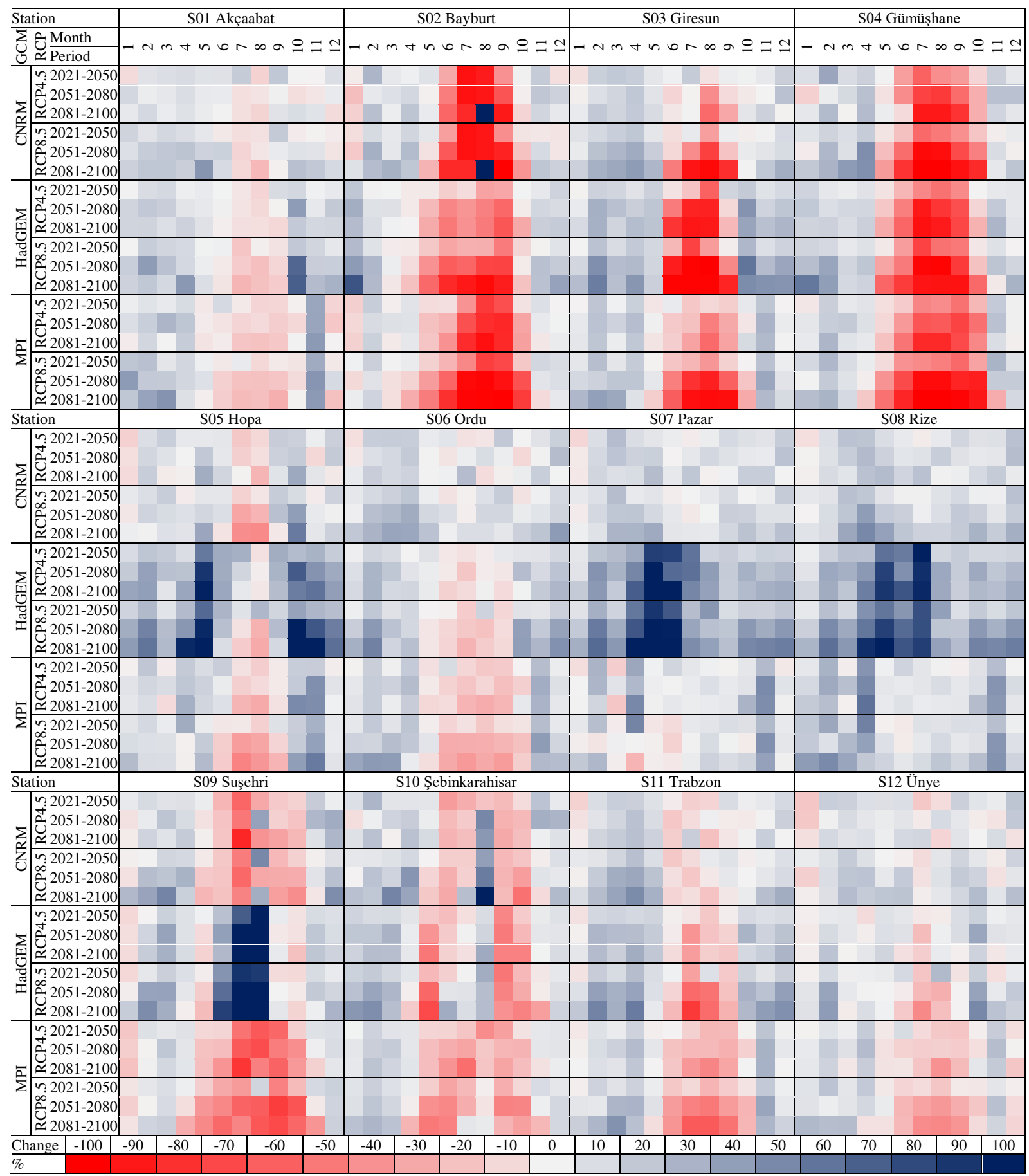

Figure 8. Precipitation changes (in \%) in relation to the 1980-2005 historical scenario period for RCP4.5 and RCP8.5 scenarios. 


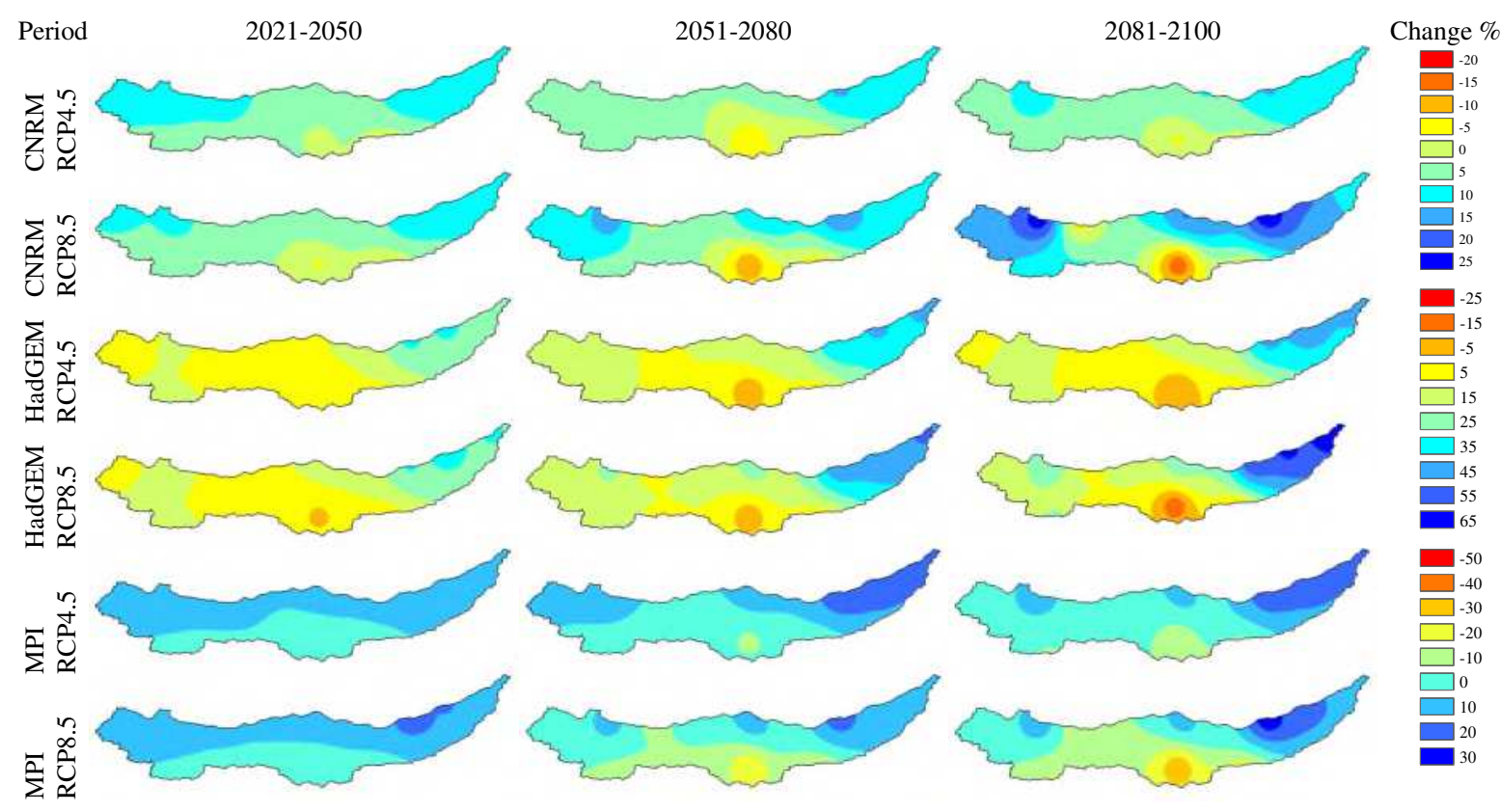

Figure 9. Spatial distribution for the change of annual mean precipitation (compared to base period) in future periods under scenarios RCP4.5 and RCP8.5 